\title{
Intraseasonal oscillations and interannual variability of surface winds over the Indian monsoon region
}

\author{
B N Goswami*, D Sengupta and G Suresh Kumar \\ Centre for Atmospheric and Oceanic Sciences, Indian Institute of Science, Bangalore 560012, India \\ *e-mail: goswamy@caos.iisc.ermet.in
}

The role of intraseasonal oscillations (ISOs) in modulating synoptic and interannual variations of surface winds over the Indian monsoon region is studied using daily averaged National Centers for Environmental Prediction/National Centre for Atmospheric Research (NCEP/NCAR) reanalyses for the period 1987-1996. Two dominant ISOs are found in all years, with a period between 30-60 days and $10-20$ days respectively. Although the ISOs themselves explain only about $10-25 \%$ of the daily variance, the spatial structure of variance of the ISOs is found to be nearly identical to that of high frequency activity (synoptic disturbances), indicating a significant control by the ISOs in determining the synoptic variations. Zonal and meridional propagation characteristics of the two modes and their interannual variability are studied in detail.

The synoptic structure of the 30-60 day mode is similar in all years and is shown to be intimately related to the strong ('active') or weak ('break') phases of the Indian summer monsoon circulation. The peak (trough) phase of the mode in the north Bay of Bengal corresponds to the 'active' ('break') phase of monsoon strengthening (weakening) the entire large scale monsoon circulation. The ISOs modulate synoptic activity through the intensification or weakening of the large scale monsoon flow (monsoon trough). The peak wind anomalies associated with these ISOs could be as large as $30 \%$ of the seasonal mean winds in many regions. The vorticity pattern associated with the 30-60 day mode has a bi-modal meridional structure similar to the one associated with the seasonal mean winds but with a smaller meridional scale. The spatial structure of the 30-60 day mode is consistent with fluctuations of the tropical convergence zone (TCZ) between one continental and an equatorial Indian Ocean position. The 10-20 day mode has maximum amplitude in the north Bay of Bengal, where it is comparable to that of the 30-60 day mode. Elsewhere in the Indian Ocean, this mode is almost always weaker than the 30-60 day mode. In the Bay of Bengal region, the wind curl anomalies associated with the peak phases of the ISOs could be as large as $50 \%$ of the seasonal mean wind curl. Hence, ISOs in this region could drive significant ISOs in the ocean and might influence the seasonal mean currents in the Bay.

On the interannual time scale, the NCEP/NCAR reanalysed wind stress is compared with the Florida State University monthly mean stress. The seasonal mean stress as well as interannual standard deviation of monthly stress from the two analyses agree well, indicating absence of any serious systematic bias in the NCEP/NCAR reanalysed winds. It is also found that the composite structure of the 30-60 day mode is strikingly similar to the dominant mode of interannual variability of the seasonal mean winds indicating a strong link between the ISOs and the seasonal mean. The ISO influences the seasonal mean and its interannual variability either through increased/decreased residence time of the TCZ in the continental position or through occurrence of stronger/weaker active/break spells. Thus, the ISOs seem to modulate all variability in this region from synoptic to interannual scales.

Keywords. Surface winds; intraseasonal oscillations; interannual variability. 


\section{Introduction}

The Indian summer monsoon is known to have intraseasonal fluctuations that are manifested in the form of active and weak (or break) spells of monsoon rainfall. These active and break spells of the monsoon are associated with fluctuations of the tropical convergence zone (TCZ) (Yasunari 1979, 1980, 1981; Sikka and Gadgil 1980; Gadgil 1988). The TCZ over the Indian monsoon region represents the ascending limb of the regional Hadley circulation. Thus the intraseasonal oscillations (ISO) of the monsoon are essentially a manifestation of fluctuations of the regional Hadley circulation. Therefore, these oscillations should be seen in other circulation features (e.g. wind) and precipitation as well. These fluctuations initially noted in Indian station data (Keshavamurthy 1973; Dakshinamurti and Keshavamurthy 1976) were later shown to be related to coherent fluctuations of the regional Hadley circulation (Krishnamurti and Subramaniam 1982; Murakami et al 1984; Mehta and Krishnamurti 1988; Hartman and Mitchelson 1989). The intraseasonal oscillation of the monsoon, though not periodic, has two dominant bands in the spectrum (Krishnamurti and Bhalme 1976; Krishnamurti and Ardunay 1980; Yasunari 1980). One band contains the period between 10 and 20 days while the other contains period between 30 and 50 days. The 10-20 day oscillation has a clear westward propagation and a weak northward propagation in the northern hemisphere (NH). The 30-50 day oscillation has a northward and eastward propagation over the monsoon region.

Most studies so far on ISOs of the monsoon have been limited to upper air data, outgoing long wave radiation (OLR) or precipitation. No careful documentation of the ISOs of surface wind is available. This is because reliable daily surface wind data covering the large Indian Ocean region was not readily available. With the availability of the NCEP/NCAR reanalyses products (see section 2 ), we are now in a position to examine the ISOs of the surface wind. As the surface winds drive oceanic circulation, it is possible that ISOs of the surface wind are responsible for driving intraseasonal variability in the Indian Ocean. Recently, direct measurements by Schott et al (1994) using three moorings and shipboard profiling during January 1991 to February 1992 show a clear oscillation with a period of about one month in the upper ocean zonal transport off Sri Lanka. These intraseasonal oscillations in the ocean transport (or currents) are most vigorous during the south-west monsoon season, when the monsoonal ISOs are also most vigorous.

The Indian summer monsoon is a unique phenomenon in the global tropics. The seasonal mean monsoon (precipitation as well as circulation) is determined by seasonal migration of the mean position of the zonal
TCZ in this region from south of the equator during the northern winter to about $25^{\circ} \mathrm{N}$ in northern summer. It is also known that the TCZ does not remain stationary during the summer season but fluctuates intermittently between two favoured positions (Sikka and Gadgil 1980). One such region is over the Indian continent along the 'monsoon trough' extending from north Bay of Bengal to north-western India. The other favoured position is over the warm waters in the equatorial Indian Ocean. The fluctuations of the TCZ within the season are intimately linked to ISOs of the monsoon. The relative residence time of the TCZ in the two favoured locations is expected to determine the seasonal mean precipitation and circulation. During an average northern summer the residence time over the continental position is higher resulting in higher seasonal precipitation over the continent during this season. Changes in the relative residence time in the two favoured locations could change the seasonal mean. Therefore, the statistics of the ISOs are expected to be related to the seasonal mean and its interannual variability. Moreover, the synoptic disturbances (lows and depressions) in this region generally form in the shear zone of the TCZ. Since the ISOs are linked to fluctuations of the TCZ, it is logical to expect that the ISOs modulate synoptic activity too.

A conceptual model of how the ISOs can influence the interannual variability of the monsoon was proposed by Goswami (1994). The relationship between the intraseasonal variability and interannual variability (IAV) of the Indian monsoon, however, has not been clearly documented from observations. Not many studies have actually addressed the question. Mehta and Krishnamurti (1988) examined the interannual variability of the 30-50 day mode in the winds, at 850 and $200 \mathrm{mb}$ levels for the period 1980 to 1984 using European Centre for Medium Range Weather Forecasts (ECMWF) operational analysis. They examined mainly the variations in the northward propagation characteristics and did not attempt to relate these to variations of the seasonal mean. Moreover, the ECMWF operational analysis was deficient in representing tropical divergent circulation in that period (Trenberth and Olson 1988). Therefore, the results of Mehta and Krishnamurti (1988) could have been influenced by this bias in the analysis. Singh and Kripalani (1990) and Singh et al (1992) used long records of daily rainfall data over the Indian continent and examined the 30-50 day oscillation of the precipitation. They could not come to a clear conclusion regarding the relationship between ISOs and IAV of the monsoon rainfall. Ahlquist et al (1990) studied radiosonde observations at 12 Indian stations between 1951 and 1978. They examined ISOs with period longer than 10 days but did not try to relate the ISOs with IAV of the monsoon. Recently, Ferranti et al (1997) studied the relationship between intraseasonal 

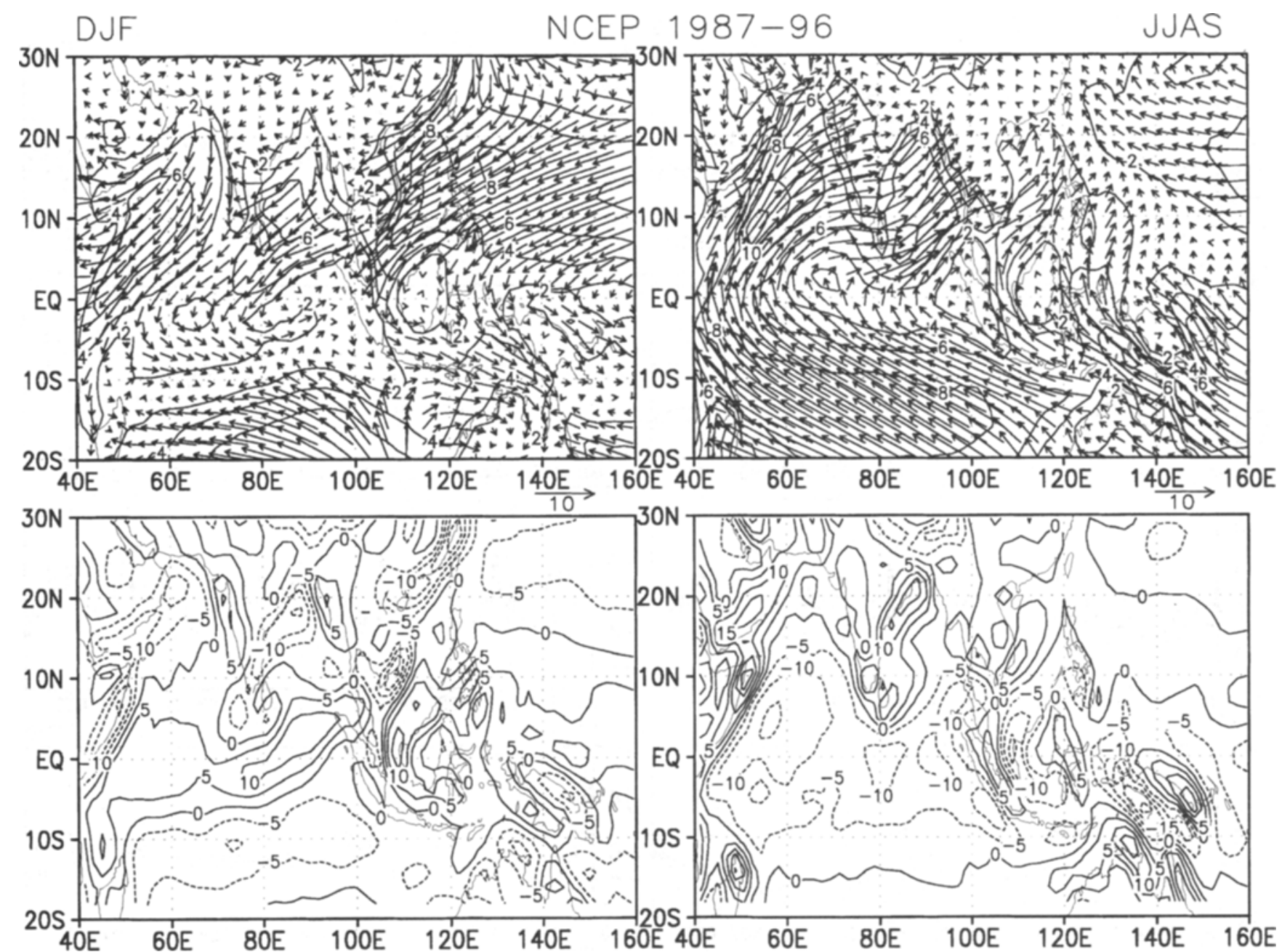

Figure 1. Climatological mean surface wind vectors and isotachs $\left(\mathrm{ms}^{-1}\right)$ for winter (DJF) and summer (JJAS) seasons based on ten year period (1987-1996). Corresponding vorticity (in units of $10^{-6} \mathrm{~s}^{-1}$ ) is also shown (lower panels).

and interannual variability over the monsoon region using data from five 10-year simulations of the ECMWF GCM differing only in their initial conditions. They examined simulated precipitation and $850 \mathrm{mb}$ relative vorticity in detail and showed that monsoon fluctuations within a season and within different years have a common mode of variability with a bimodal meridional structure in the precipitation. While the structure of the common mode of variability is qualitatively consistent with fluctuations of the TCZ in the two favoured locations, their results suffer from some systematic errors inherent in the ECMWF GCM simulation of the Indian summer monsoon. The model underestimates precipitation over the north Bay of Bengal and the monsoon trough zone. This reflects in their interannual mode having a high amplitude only east of $80^{\circ} \mathrm{E}$ both in precipitation and low level vorticity.

The two major objectives of this study are to document the mean structure and statistics of the ISOs and their interannual variability, and to examine the relationship between the ISOs and IAV of the mean monsoon.

\section{Data and methodology}

The study uses daily zonal ( $u$ ) and meridional (v) winds at 10 metre height derived from the NCEP/NCAR reanalyses for the period 1987 to 1996 . The NCEP reanalysis project used a frozen state-of-the-art analysis system (the Global Data Assimilation System, GDAS), using past data, from 1957 to the present. This project involves the recovery of land surface, ship, rawinsonde, pibal, aircraft, satellite and other data; quality controlling and assimilating these data with the GDAS that is kept unchanged over the reanalyses period 1957-96. This eliminates artificial jumps. In addition to using a state-of-the-art analysis scheme, the reanalyses also use delayed observations, increasing the reliability of the surface wind products. The NCEP 40-year reanalysis is a research quality dataset suitable for weather and short term climate research (Kalnay et al 1996). The data are on a T62 Gaussian grid (192 long. x 94 lat.) points. In order to compare the interannual variability derived from NCEP reanalyses, we also use the monthly mean surface wind analysis of Florida State University (Legler et al 1989). 

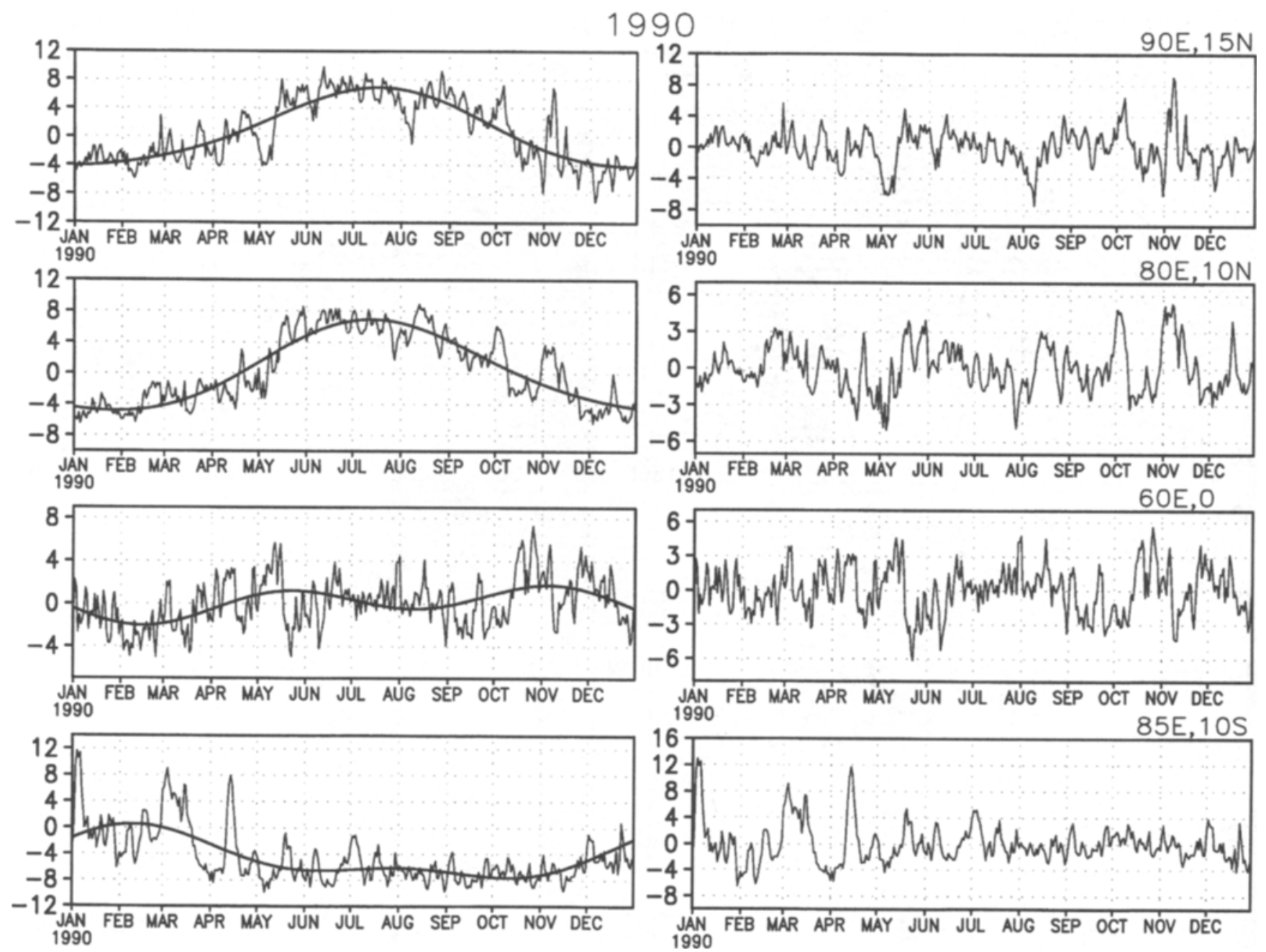

Figure 2. (Left): Time series of zonal winds $\left(\mathrm{ms}^{-1}\right)$ at some selected locations for 1990 (thin line) and that constructed based on annual and semi-annual harmonics (thick line). (Right): Respective anomalies $\left(\mathrm{ms}^{-1}\right)$ of $u$ after removal of the annual and semiannual harmonics.

The surface winds in the monsoon region are characterized by a strong seasonal cycle. The summer (June-July-August-September; JJAS) and winter (December-January-February; DJF) mean winds in figure 1 show the strength of the seasonal mean and amplitude of the seasonal cycle of the surface wind. The mean vorticity patterns associated with the mean wind are also shown. The raw daily data contain the seasonal cycle. An example of daily variations of zonal wind at a few points is shown in figure 2 . North of the equator, the zonal winds are typically easterly in winter turning to westerly in summer. Both zonal and meridional winds contain annual and semi-annual components. As we are primarily interested in bringing out the dominant intraseasonal oscillations, it is necessary to remove the seasonal changes. A harmonic analysis is carried out, and daily anomalies are calculated by removing the annual and semi-annual harmonics from the daily data for each year. The sum of annual and semi-annual harmonics at the selected points are shown by thick lines on the left panels in figure 2, while the right panels show the anomalies. In addition to high frequency fluctuations, intraseasonal oscillations are evident in these wind anomalies. The characteristics of the intraseasonal oscillations are studied using different techniques as described in the next section.

\section{Intraseasonal oscillations}

Over the monsoon region (north of $10^{\circ} \mathrm{N}$ ) the ISOs are most active during the Indian summer monsoon season (May to October). To make reliable estimates of the spectra using fast Fourier transform (FFT), while avoiding the winter season, we used daily anomalies from the beginning of March for 256 days. The spectra are calculated at all latitudinal points along a number of longitudes. As an example, the spectra of zonal wind at different latitudes along two longitudes for 1990 are shown in figure 3. It is clear that there are two major peaks, one with period 


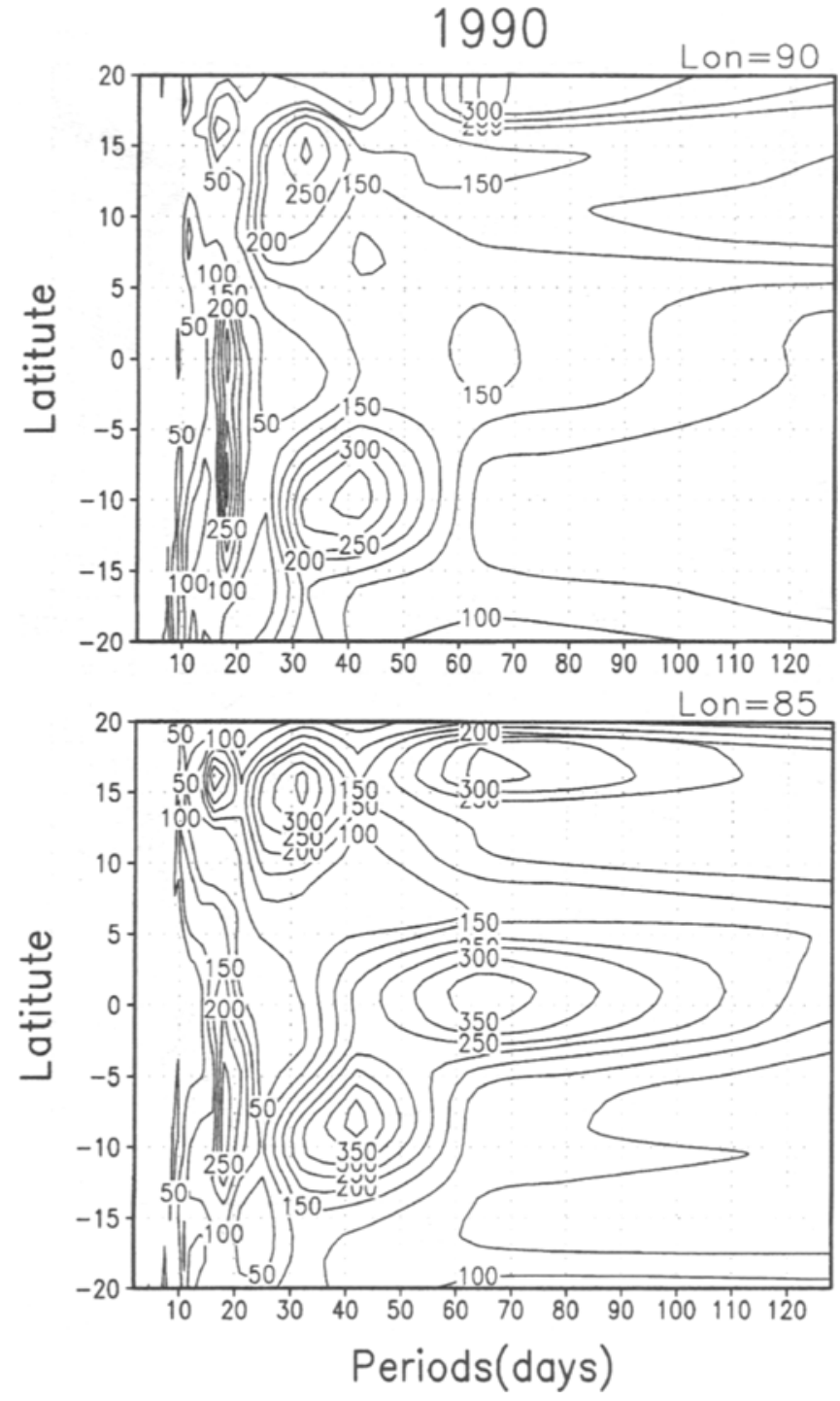

Figure 3. Power spectra of surface zonal winds for 1990 between $20^{\circ} \mathrm{S}$ and $20^{\circ} \mathrm{N}$ along two longitudes. Units are $\left(\mathrm{ms}^{-1}\right)^{2}$ day.

around 40 days and the other with period around 18 days. These two dominant peaks are consistently seen at both longitudes. In addition, another peak around 62 days is seen at $85^{\circ} \mathrm{E}$ with a weak peak at $90^{\circ} \mathrm{E}$. The 60 -day mode has largest amplitude around the equator while the 40-day mode has largest amplitude between 10 and 15 degrees latitude. The 40-day mode is the monsoonal intraseasonal oscillation in 1990 while the 60-day mode is likely to be associated with the equatorial Madden-Julian oscillation. Those periods with peak power seen consistently at most off equatorial latitudes and at all longitudes are considered the dominant monsoonal intraseasonal oscillations. In most years dominant periods are seen to lie between 30 and 60 days and between 10 and 20 days. We shall refer to these two modes as the 30-60 day mode and 10-20 day mode respectively. The dominant periodicities are selected for all the years in this manner. To study the detailed structure and propagation char- acteristics of the ISOs in 1990, a Butterworth bandpass filter (Murakami 1979) with peak response at 40 days and half responses at 30 days and 53 days is used to isolate the ISO with period around 40 days. Similarly, a Butterworth filter with peak response at 18 days and half response at 14 days and 23 days is used to isolate the ISO with period around 18 days. Finally, a high pass filter is used to remove from the data all periods greater than 10 days, to bring out the high-frequency ('synoptic') signal.

The standard deviation of the zonal wind associated with the ISOs during the northern summer (May 1 to October 31) of 1990 is compared with that of the total daily zonal wind and the synoptic activity in figure 4 . The figure shows the standard deviations of the daily winds, and that of the filtered winds in the 30-60 day band, 10-20 day band and 2-10 day (synoptic) band respectively. It is clear that there are three centres of action in the Indian Ocean, one over the north Arabian Sea, one over the north Bay of Bengal and the third over the south equatorial trade wind belt. Both the 30-60 day mode and the 10-20 day mode have significant (up to one third of the total) amplitude in the Bay of Bengal and the south equatorial trade wind belt. In some years, the ISOs also have significant amplitude in the Arabian Sea. The fact that the centres of synoptic (high pass filtered) activity and those of the ISOs' activity are collocated, indicates that the ISOs are instrumental in modulating and organizing the synoptic activity. How the ISOs achieve this by modifying the large scale environment will be illustrated in section 6 .

\subsection{The 30-60 day mode}

To further investigate the structure and propagation characteristics of the 30-60 day mode, we calculated $\mathrm{lag} /$ lead correlations of the filtered zonal wind with respect to a reference point at $90^{\circ} \mathrm{E}$ and $15^{\circ} \mathrm{N}$, located at a point of high activity of the 30-60 day mode (figure 4). The lag zero correlations shown in figure 5 illustrate that over the monsoon region, the ISO has a meridional scale of about $30^{\circ}$ latitude. The east west structure of this monsoon ISO is different from the Madden-Julian oscillation in that it does not have a traditional wave number one character. It has a large zonal scale of about $120^{\circ}$ longitude in the monsoon region. In the global tropics it is also characterized by one pole in the Asian Monsoon region and another (opposite) pole in the south Eastern Pacific and Amazonian region. North-south and east-west propagation characteristics of the mode are illustrated in figure 6 where correlations are plotted for various lags as a function of latitude or longitude. From the left panel, it is noted that the mode has a northward propagation between $5^{\circ} \mathrm{N}$ and $25^{\circ} \mathrm{N}$ with an average speed of propagation of about $0.5^{\circ}$ latitude/day. South of the equator it appears to be nearly stationary. 


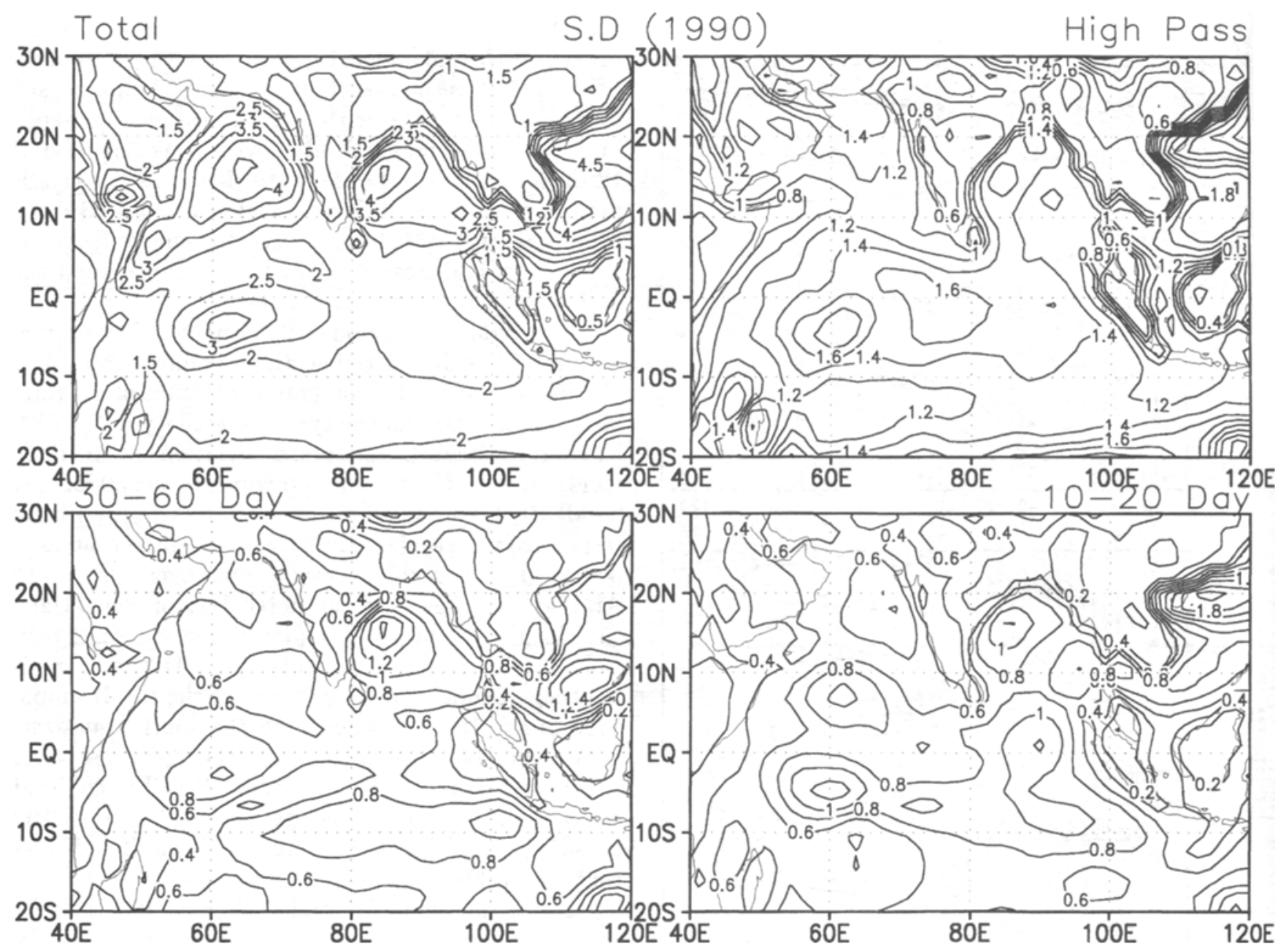

Figure 4. Standard deviation of zonal wind anomalies $\left(\mathrm{ms}^{-1}\right)$ for 1990 during the summer season (May 1st to October 31st). (Top left) Unfiltered daily, (top right) high pass filtered with period less than 10 days, (bottom left) 30-60 day filtered, (bottom right) 10-20 day filtered.

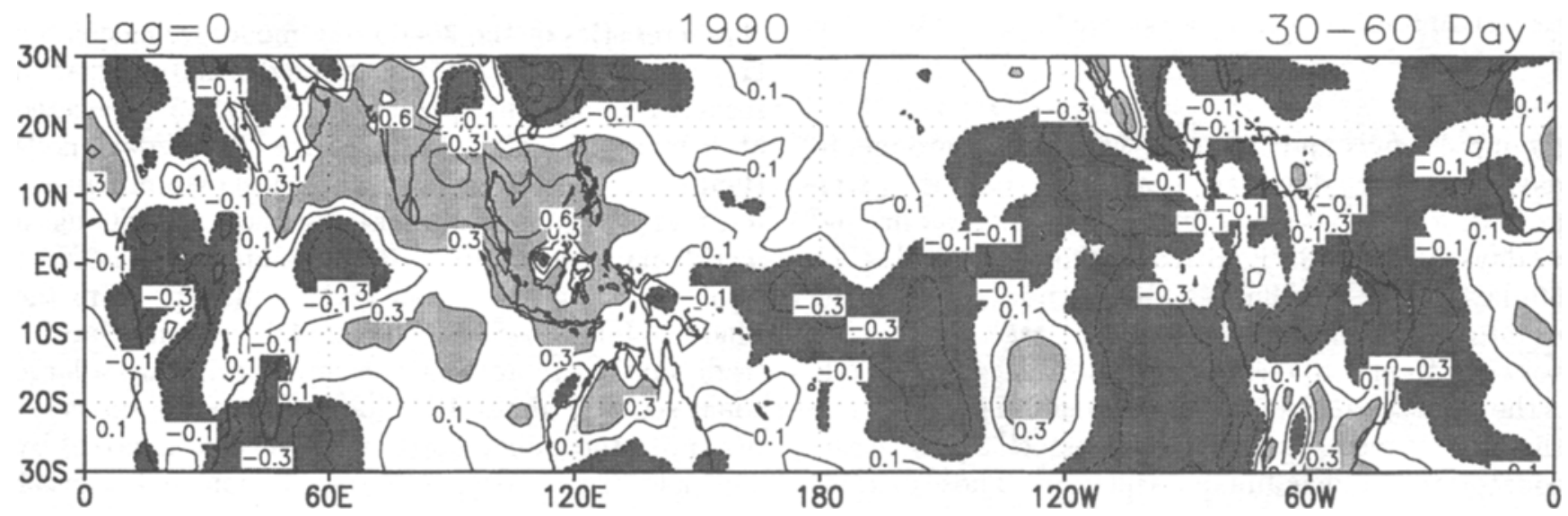

Figure 5. Lag zero correlations of the 30-60 day filtered zonal winds with respect to a reference point at $\left(90^{\circ} \mathrm{E}, 15^{\circ} \mathrm{N}\right)$ for 1990 .

Figure 6 also indicates a half wave length of about 15 degrees latitude, consistent with figure 5 . The right panel shows that the mode has a clear eastward propagation in the monsoon region. Estimated average eastward speed of propagation is about $9^{\circ}$ longitude/day.
The large scale structure of the oscillation is important in modifying the mean monsoon flow (figure 1) and hence in modulating the synoptic activity. Different researchers have followed different ways of elucidating the structure of the ISOs. Krishnamurti 

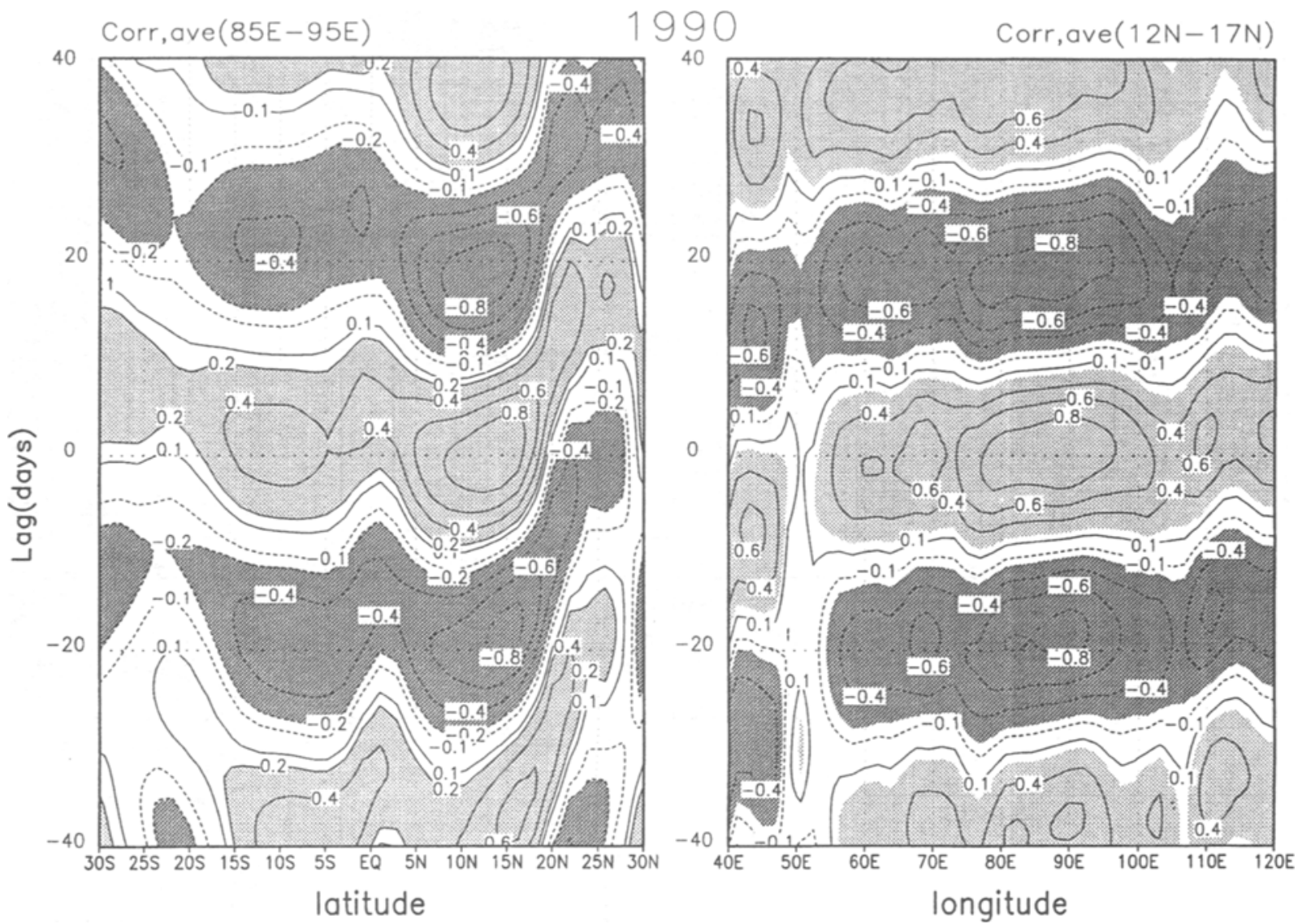

Figure 6. (Left): Correlations with respect to a reference point at $\left(95^{\circ} \mathrm{E}, 15^{\circ} \mathrm{N}\right)$ to $30-60$ day filtered zonal winds for different lags averaged over $\left(85^{\circ} \mathrm{E}-95^{\circ} \mathrm{E}\right)$ as a function of latitude. (Right): Correlations averaged over $12^{\circ} \mathrm{N}-17^{\circ} \mathrm{N}$ as a function of longitude over the monsoon region.

and Subramaniyan (1982) examined the evolution of $850 \mathrm{mb}$ circulation anomaly streamlines during a typical oscillation. Murakami and Nakazawa $(1984,1985)$ used phase composites to illustrate the typical evolution of the oscillation during a cycle. We anticipate that ISO of the surface wind over the monsoon are linked with 'active' and 'break' phases of the monsoon. We try to bring this out following a phase composite technique similar to that used by Murakami and Nakazawa. We filter the meridional wind using the same band pass filter. Then a reference point is selected at $\left(85^{\circ} \mathrm{E}, 10^{\circ} \mathrm{N}\right)$. The filtered zonal wind at the reference point is used to identify the phases of the oscillations. The reference point is selected slightly to the south of the mean position of the 'monsoon trough' so that an active (or a break) phase of the monsoon would be associated with strong positive (negative) zonal wind anomalies at this point. We define the peak, or crest, of the oscillation as that phase which is associated with maximum positive (i.e. eastward) zonal wind anomalies. Each oscillation is divided into eight phases or categories and zonal and meridional winds corresponding to each category are averaged over three or four oscillations during the summer season (1st May to 15th October). In figure 7, we show the composite vector wind anomalies over the whole domain associated with the crest (category 7 or active) and trough (category 3 or break) of the zonal wind oscillation at the reference point. It is interesting to note that the crest (or active) phase of oscillation is associated with a strengthening of the large scale monsoon circulation while the trough (or break) phase is associated with a weakening of the monsoon circulation. A comparison of these vector wind anomalies with the seasonal mean (figure 1) shows that the 30-60 day oscillation can modify the seasonal mean substantially, increasing or decreasing it by up to $25 \%$. The anomalous vorticity patterns associated with mean 'active' or 'break' phases of the 30-60 day mode are also shown in figure 7 . It is characterized by a bimodal structure with a positive vorticity band north of approximately $10^{\circ} \mathrm{N}$ and a negative vorticity band south of approximately $10^{\circ} \mathrm{N}$. The vorticity structure of the 30-60 day mode is similar to the vorticity pattern associated with the summer mean winds shown in figure 1 , except that the former has smaller meridional scale. Another important point to note is that positive (negative) anomalous wind curl associated with active (break) phase of this mode in the north Bay of Bengal is 


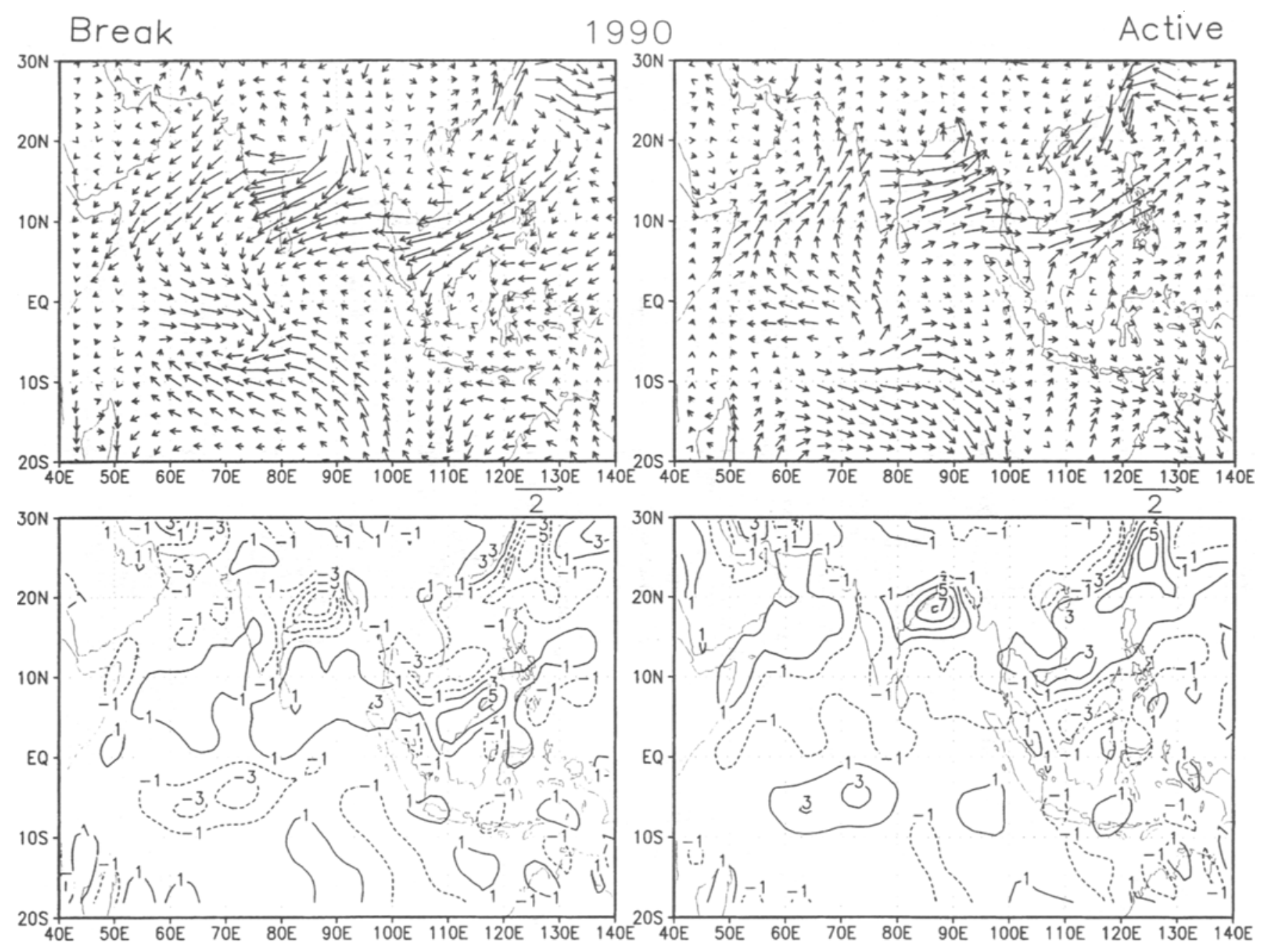

Figure 7. Composite vector wind anomalies for 1990 (top) and corresponding vorticity (in units of $10^{-6} \mathrm{~s}^{-1}$ ) (bottom) associated with the 'active' and 'break' phases (peak and trough phases of the zonal winds at a reference point in the north Bay of Bengal) respectively of the 30-60 day mode.

comparable to the mean wind curl over the same region (figure 1). This implies that the ISO may have a strong control on the wind driven ocean circulation in this region. This point will be discussed further in section 4 .

\subsection{The 10-20 day mode}

In this section, the structure and propagation characteristics of the 10-20 day mode are studied. A reference point is again selected at $\left(85^{\circ} \mathrm{E}, 10^{\circ} \mathrm{N}\right)$. The lag zero correlation pattern (not shown) indicates that this mode has a regional character and has coherent fluctuations primarily over the Asian monsoon region. North-south and east-west propagation characteristics of the mode are shown in figure 8 . The meridional scale of this mode in the monsoon region is similar to that of the $30-60$ day mode (about $30^{\circ}$ latitude). The 10-20 day mode shows a transition from southward propagating character to northward propagating character around $5^{\circ} \mathrm{N}$ in 1990 (figure 8). However, the mode is clearly westward propagating over the Indian region.

The phase composite for the 10-20 day mode is studied with respect to a reference point $\left(90^{\circ} \mathrm{E}, 20^{\circ} \mathrm{N}\right)$ which lies to the north of the monsoon trough over the north Bay of Bengal. The composite vector wind anomalies and associated vorticity for categories 7 and 3 (trough or active and crest or break phases of the filtered zonal wind at the reference point) are shown in figure 9. It may be noted that in this case about 8-10 oscillations are available for averaging. The wind anomalies associated with the crest and trough phases of this mode are generally smaller than those associated with the 30-60 day mode in this year. The composite vorticity pattern is also similar to that associated with the 30-60 day mode but is weaker in magnitude. Over the north Bay of Bengal, this mode too has a positive (negative) vorticity maximum associated with active (break) phases of the mode. Depending on the phase relationship with the 30-60 day mode, the 10-20 day mode can reinforce 

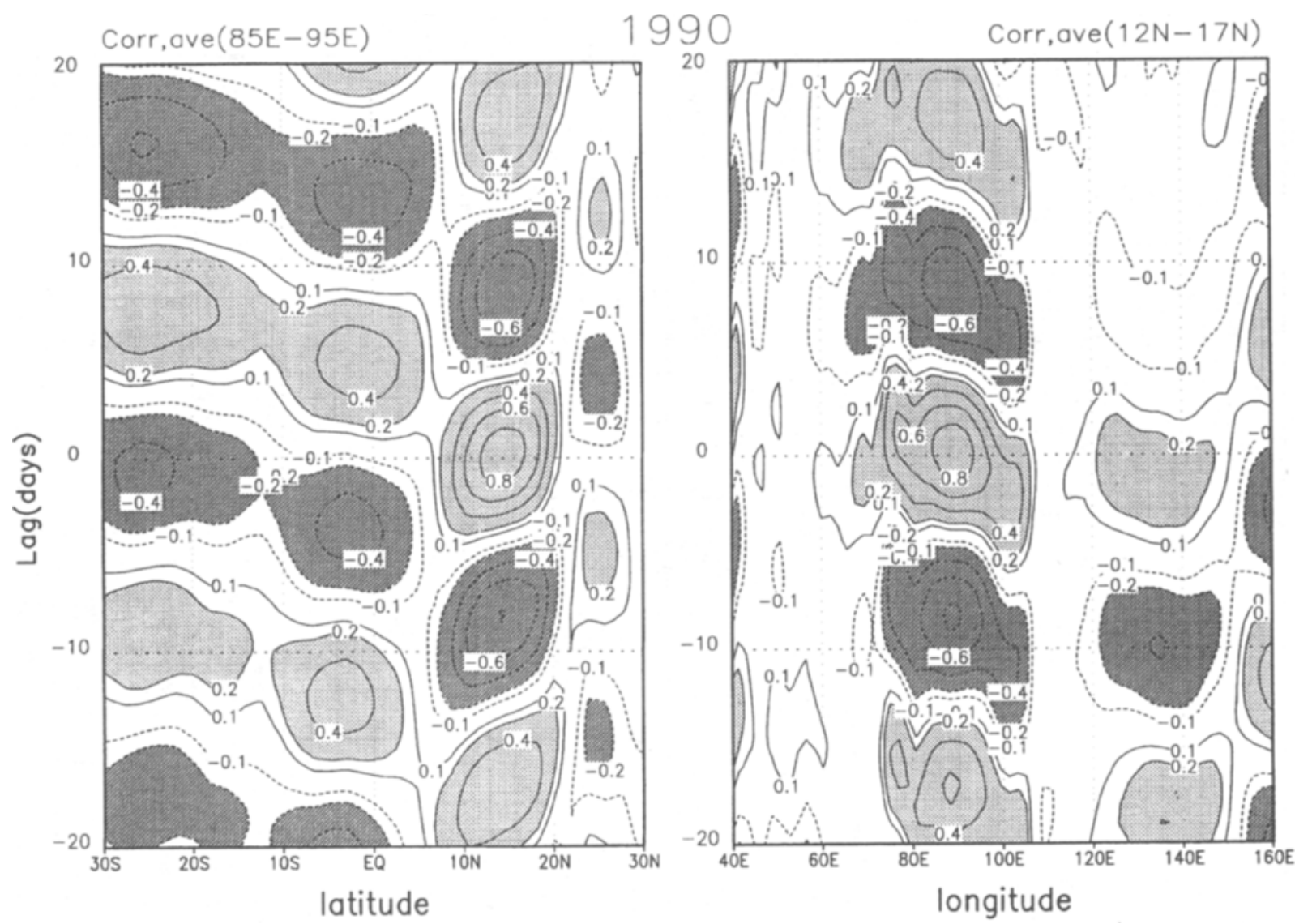

Figure 8. Same as figure 6, but for the 10-20 day mode for 1990 .

the contribution of the ISOs to the curl of the wind in this region. We shall discuss this point again in section 4 .

\section{Interannual variations of ISO}

Using the same techniques as described in section 3 , the period, amplitude, propagation characteristics and spatial structures of the ISOs are studied for all the years from 1987 to 1996. There is considerable variation in these attributes of the ISOs from year to year. In this section, we discuss this interannual variability.

\subsection{Periods}

The spectra for all years show that there are always two dominant periods as seen in 1990. However, the peak period within the lower frequency band varies from 30 days to 60 days. Similarly, the peak period within the higher frequency band varies between 10 and 20 days. This is the reason we call the two ISOs the 30-60 day mode and the 10-20 day mode. The peak periods and periods corresponding to the half response of the band pass filters used to extract the modes in different years are summarized in table 1. It may be noted that the sharpness of the filters are varied slightly from one year to another to minimize the overlap of the two filters.

\subsection{Amplitude}

The peak amplitude and the location of the peak can vary from one year to another. For example, the standard deviations of the daily unfiltered zonal winds, the 30-60 day filtered, the 10-20 day filtered and the high pass filtered zonal winds for 1996 are shown in figure 10. It is seen that both the 30-60 day mode and the 10-20 day mode have maximum amplitude in three regions of the Indian Ocean coinciding more or less with the three centres of maximum variability of the high pass filtered zonal winds. In contrast to 1990, the ISO has significant amplitude over the north Arabian Sea in 1996. As in 1990 and other years, the ratio between the maximum amplitude of unfiltered wind to the maximum amplitude of the ISOs varies between $2: 1$ and $3: 1$.

\subsection{Meridional and zonal propagation}

The meridional propagation of the 30-60 day mode is variable from one year to another. The meri- 

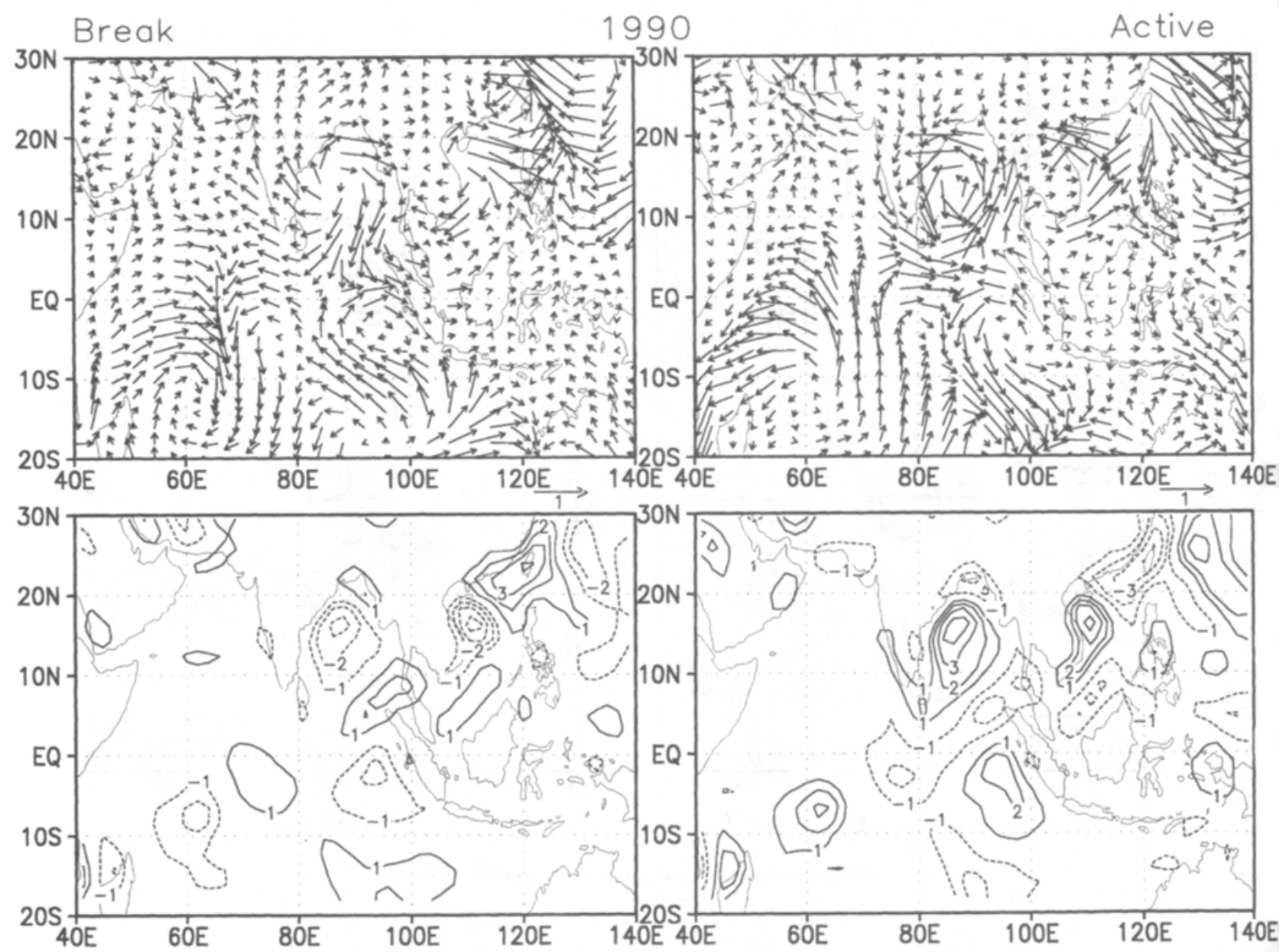

Figure 9. Same as figure 7, but for the 10-20 day mode for 1990 .

Table 1. Dominant periods in days and periods in days at which the Butterworth filters used to isolate the dominant periods have half response (within parenthesis).

\begin{tabular}{lll}
\hline Year & \multicolumn{1}{c}{ Mode I } & \multicolumn{1}{c}{ Mode II } \\
\hline 1987 & $30(20,45)$ & $16(12,21)$ \\
1988 & $50(40,62.5)$ & $20(14,28.5)$ \\
1989 & $30(20,45)$ & $16(12,21)$ \\
1990 & $40(30,53)$ & $18(14,23)$ \\
1991 & $40(25,64)$ & $18(14,23)$ \\
1992 & $30(23,39)$ & $18(14,23)$ \\
1993 & $30(20,45)$ & $16(12,21)$ \\
1994 & $30(20,45)$ & $16(12,21)$ \\
1995 & $30(20,45)$ & $16(12,21)$ \\
1996 & $30(20,45)$ & $16(12,21)$ \\
\hline
\end{tabular}

dional propagation characteristics for the 30-60 day and the 10-20 day mode for all the years are summarized in table 2. As can be seen from this table, the propagation of the 30-60 day mode does not have a robust and universal character. During most years, the mode is northward propagating or stationary north of $10^{\circ} \mathrm{N}$. South of this location it is either southward propagating or stationary in most years. The lag correlations provide an average picture of the propagation characteristics. We also examined time-latitude sections of the filtered anomalies. It is seen (not shown) that even when there is average northward propagation in a year, it is not uniform over the three or four pulses or oscillations during the summer season. There may be strong northward propagation in one or two pulses while the other pulses could be stationary or even southward propagating. The meridional propagation of the 10-20 day mode is somewhat more systematic. With the exception of 1990, 1995 and 1996, when there was some northward propagation of the mode between $10^{\circ} \mathrm{N}$ and $20^{\circ} \mathrm{N}$, all other years are dominated by southward propagation.

The zonal propagation for both the modes is robust and consistent in almost all the years. The 30-60 day mode is clearly eastward propagating in this region for all the years. Small variations from year to year are found only in the speed of propagation. The speed of eastward propagation generally varies between $8^{\circ}$ and $10^{\circ}$ longitude per day. Similarly, the zonal propagation for the 10-20 day mode is consistently westward in the monsoon region, the average speed 


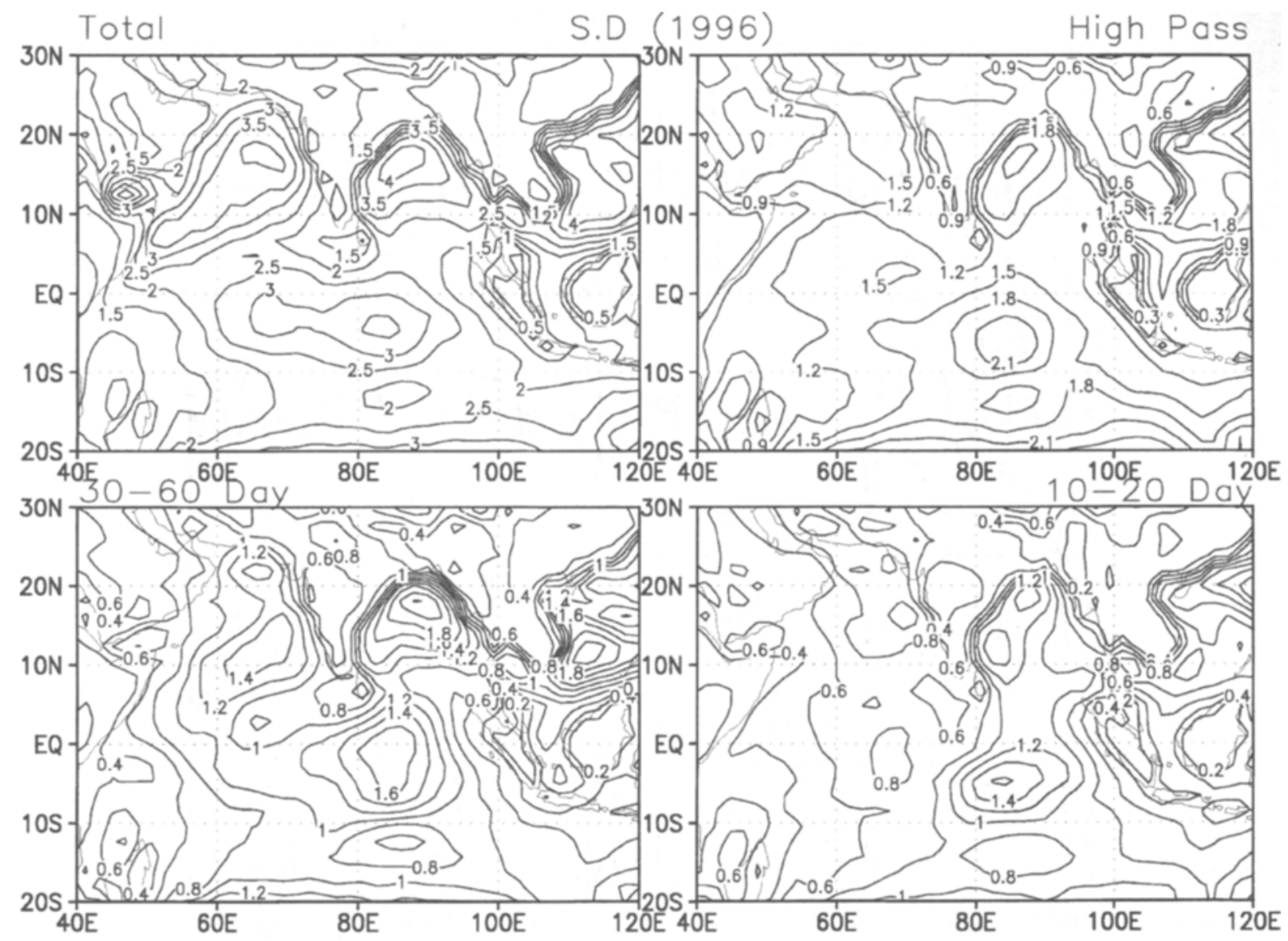

Figure 10. Same as figure 4, but for 1996 .

Table 2. Interannual variations of meridional propagation of the two intraseasonal modes over the monsoon region.

\begin{tabular}{|c|c|c|}
\hline Year & $30-60$ day mode & 10-20 day mode \\
\hline 1987 & $\begin{array}{l}\text { Southward propagation south of } 10^{\circ} \mathrm{N} \text {. } \\
\text { Stationary north of } 10^{\circ} \mathrm{N} \text {. }\end{array}$ & $\begin{array}{l}\text { General tendency of southward } \\
\text { propagation betweeen } 25^{\circ} \mathrm{N} \text { to } 25^{\circ} \mathrm{S} \text {. } \\
\text { Approximate speed: } 2^{\circ} \text { lat./day. }\end{array}$ \\
\hline 1988 & $\begin{array}{l}\text { Slow northward propagation clearly seen from southern } \\
\text { hemisphere to about } 25^{\circ} \mathrm{N} \text {. Average speed approximately } \\
0.5^{\circ} \text { lat/day. }\end{array}$ & $\begin{array}{l}\text { Similar to } 1987 \text {. Southward propagation between } \\
15^{\circ} \mathrm{N} \text { and } 25^{\circ} \mathrm{S} \text {; Approximate speed: } \sim-2^{\circ} \text { lat./day. }\end{array}$ \\
\hline 1989 & $\begin{array}{l}\text { Southward propagation seen from } 20^{\circ} \mathrm{N} \text { to } 20^{\circ} \mathrm{S} \text {. } \\
\text { Speed approximately } 1.2^{\circ} \text { lat/ day. }\end{array}$ & $\begin{array}{l}\text { Similar to } 1987 \text {. Southward propagation between } \\
20^{\circ} \mathrm{N} \text { and } 20^{\circ} \mathrm{S} \text {. Approximate speed: } \sim-2^{\circ} \text { lat./day. }\end{array}$ \\
\hline 1990 & $\begin{array}{l}\text { Northward propagation north of } 5^{\circ} \mathrm{N} \text { and stationary south } \\
\text { of this location. Approx. propagation speed: } 0.6^{\circ} \text { lat/ day. }\end{array}$ & $\begin{array}{l}\text { Northward propagation between } 5^{\circ} \mathrm{N} \text { and } 20^{\circ} \mathrm{N} \text { and } \\
\text { southward propagation south of } 5^{\circ} \mathrm{N} \text {. }\end{array}$ \\
\hline 1991 & $\begin{array}{l}\text { Northward propagation north of the equator (approx. } \\
\text { speed: } 0.75^{\circ} \text { lat./day) and indication of southward } \\
\text { propagation south of the equator. }\end{array}$ & $\begin{array}{l}\text { Southward propagation between } 5^{\circ} \mathrm{N} \text { and } 20^{\circ} \mathrm{S} \text { and } \\
\text { stationary between } 5^{\circ} \mathrm{N} \text { and } 20^{\circ} \mathrm{N} \text {. }\end{array}$ \\
\hline 1992 & $\begin{array}{l}\text { Northward propagation north of } 10^{\circ} \mathrm{N} \text { (approx. speed: } \\
0.75^{\circ} \text { lat./day). Southward propagation between } 10^{\circ} \mathrm{N} \\
\text { and } 5^{\circ} \mathrm{S} \text {. Stationary south of } 5^{\circ} \mathrm{S} \text {. }\end{array}$ & $\begin{array}{l}\text { Clear southward propagation between } 20^{\circ} \mathrm{N} \text { and } 15^{\circ} \mathrm{S} \text {. } \\
\text { Approx. speed: } \sim-2^{\circ} \text { lat./day. }\end{array}$ \\
\hline 1993 & $\begin{array}{l}\text { Stationary north of } 10^{\circ} \mathrm{N} \text { and southward propagation } \\
\text { between } 10^{\circ} \mathrm{N} \text { and } 20^{\circ} \mathrm{S} \text {. }\end{array}$ & $\begin{array}{l}\text { Clear southward propagation from } 25^{\circ} \mathrm{N} \text { to } 30^{\circ} \mathrm{S} \text {. } \\
\text { Approx. speed: } \sim-2^{\circ} / \text { day. }\end{array}$ \\
\hline 1994 & $\begin{array}{l}\text { Stationary north of } 10^{\circ} \mathrm{N} \text { with indication of southward } \\
\text { propagation between } 5^{\circ} \mathrm{N} \text { and } 25^{\circ} \mathrm{S} \text {. }\end{array}$ & $\begin{array}{l}\text { Southward propagation between } 25^{\circ} \mathrm{N} \text { and } 5^{\circ} \mathrm{N} \text {. } \\
\text { Stationary south of } 5^{\circ} \mathrm{N} \text {. }\end{array}$ \\
\hline 1995 & $\begin{array}{l}\text { Northward propagation between } 5^{\circ} \mathrm{N} \text { and } 25^{\circ} \mathrm{N} \text { (approx. } \\
\text { speed: } \sim 0.5^{\circ} \text { lat./day) and southward propagation } \\
\text { south of } 5^{\circ} \mathrm{N} \text {. }\end{array}$ & $\begin{array}{l}\text { Northward propagation between } 5^{\circ} \mathrm{N} \text { and } 20^{\circ} \mathrm{N} \text { and } \\
\text { southward between } 5^{\circ} \mathrm{N} \text { and } 20^{\circ} \mathrm{S} \text {. }\end{array}$ \\
\hline 1996 & $\begin{array}{l}\text { Northward propagation between } 5^{\circ} \mathrm{S} \text { and } 25^{\circ} \mathrm{N} \text { (approx. } \\
\text { speed } 0.75^{\circ} \text { lat./day). Stationary south of } 5^{\circ} \mathrm{S} \text {. }\end{array}$ & $\begin{array}{l}\text { Similar to } 1995 \text {. Northward propagation between } 5^{\circ} \mathrm{N} \\
\text { and } 20^{\circ} \mathrm{N} \text { and southward propagation } 5^{\circ} \mathrm{N} \text { and } 20^{\circ} \mathrm{S} \text {. }\end{array}$ \\
\hline
\end{tabular}




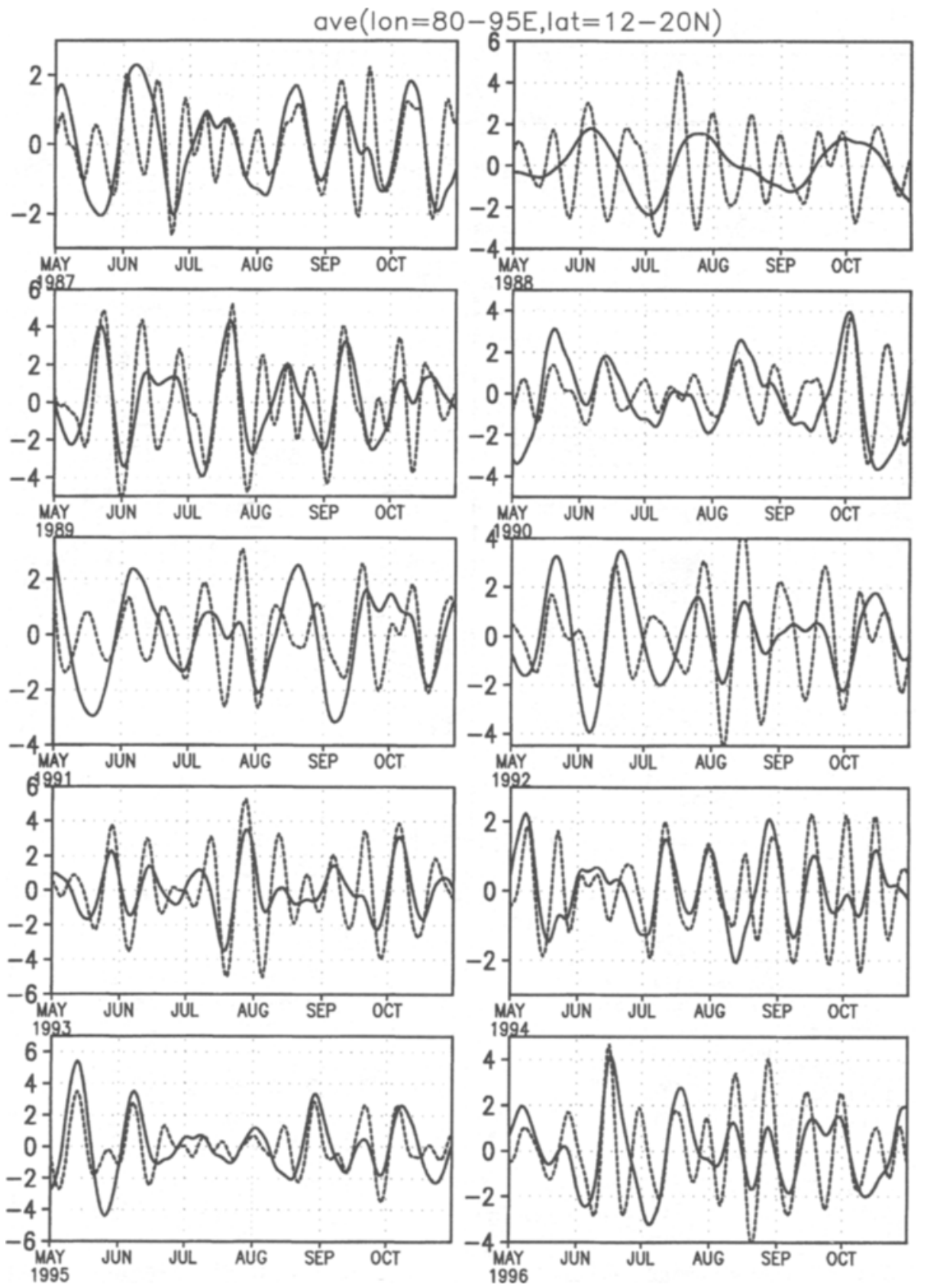

Figure 11. Time series of vorticity (units $10^{-6} \mathrm{~s}^{-1}$ ) averaged over the north Bay of Bengal $\left(80^{\circ} \mathrm{E}-95^{\circ} \mathrm{E}, 12^{\circ} \mathrm{N}-20^{\circ} \mathrm{N}\right)$ associated with the 30-60 day mode (solid) and the 10-20 day mode (dashed).

Table 3. Vorticity (in units of $10^{-6}$ ) averaged over $80^{\circ} \mathrm{E}-95^{\circ} \mathrm{E}$ and $12{ }^{\circ} \mathrm{N}-20^{\circ} \mathrm{N}$.

\begin{tabular}{lccc}
\hline Year & $\begin{array}{c}\text { June-September } \\
\text { summer monsoon wind }\end{array}$ & $\begin{array}{c}\text { Composite 'Active' phase } \\
\text { of } 30-60 \text { day oscillation }\end{array}$ & $\begin{array}{c}\text { Composite 'Active' phase } \\
\text { of the 10-20 day oscillation }\end{array}$ \\
\hline 1987 & 4.2 & 1.9 & 1.6 \\
1988 & 4.3 & 1.6 & 2.4 \\
1989 & 5.4 & 3.8 & 3.9 \\
1990 & 5.8 & 2.9 & 2.2 \\
1991 & 5.6 & 2.2 & 1.7 \\
1992 & 5.0 & 2.5 & 2.8 \\
1993 & 4.6 & 2.6 & 3.7 \\
1994 & 5.1 & 1.8 & 2.0 \\
1995 & 4.3 & 3.7 & 2.9 \\
1996 & 3.9 & 2.6 & 2.9 \\
\hline
\end{tabular}



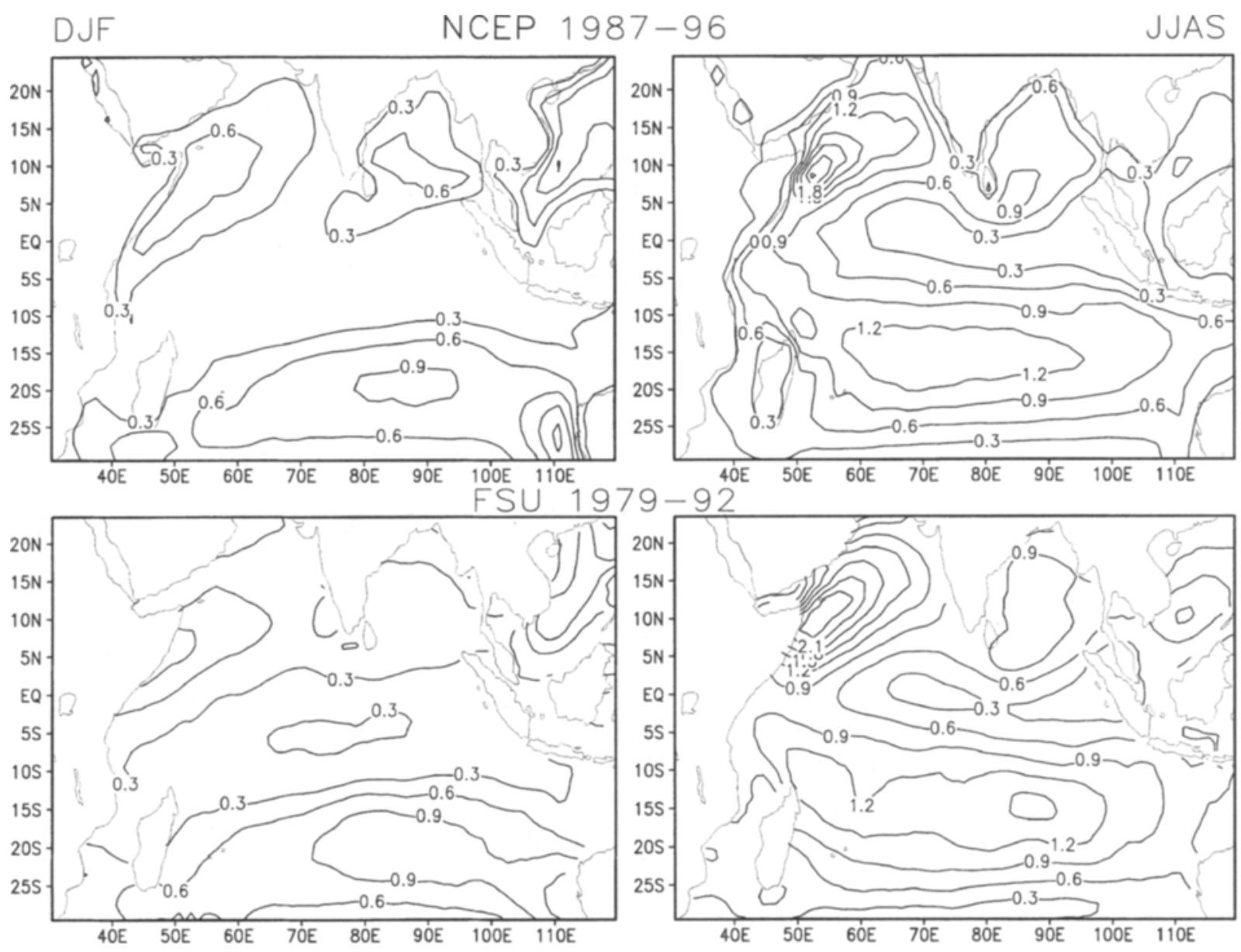

Figure 12. (Top): Climatological mean December-February (DJF) and June-September (JJAS) vector wind stress magnitude (dynes $/ \mathrm{cm}^{2}$ ) from NCEP reanalysis based on 1987-1996. (Bottom): Same as top panels but from FSU analysis based on 1979-1992.

of propagation being between $4^{\circ}$ and $6^{\circ}$ longitude per day.

\subsection{Phase composite synoptic structure}

The spatial structures of the 30-60 day mode are studied for all the years following the phase composite technique described in section 3.1 and 3.2. For all years a reference point at $\left(85^{\circ} \mathrm{E}, 10^{\circ} \mathrm{N}\right)$ or $\left(90^{\circ} \mathrm{E}, 10^{\circ} \mathrm{N}\right)$ is chosen and the composite structure of vector wind anomalies (based on filtered zonal and meridional winds) is studied corresponding to eight different phases of evolution. The synoptic structure associated with category 7 (peak zonal wind at the reference point or 'active' conditions) and category 3 (trough of zonal wind at the reference point or 'break' conditions) are qualitatively similar in all years. This synoptic structure and associated vorticity anomaly are characteristic of the mode in all years. Year to year variation is seen mainly in the peak strength of the vortices in the three centres. For example, the maximum vorticity in the north Bay of Bengal can vary from 3 units (i.e. $3 \times 10^{-6} \mathrm{~s}^{-1}$ ) in 1988 to 9 units seen in 1995. Moreover, there is some north-south shift of the region of transition between the positive and negative vorticity zones from one year to another.

The synoptic structure of the 10-20 day mode is studied using a reference point north of the monsoon trough over the Bay of Bengal in all the years. The spatial structure of the 10-20 day mode is consistently similar in all the years. This mode is associated with significant anomalies only east of $70^{\circ} \mathrm{E}$ and the largest amplitude occurs over the north Bay of Bengal. As a result, this mode assumes significance only over the Bay of Bengal where it can either reinforce or weaken the effect of the 30-60 day oscillation and thereby affect the synoptic activity and oceanic circulation in that region. This point is further illustrated in figure 11, where time series of the vorticity associated with the 30-60 day mode and with the 10-20 day mode, averaged over the north Bay of Bengal $\left(80-95^{\circ} \mathrm{E}, 12-20^{\circ} \mathrm{N}\right)$ is plotted for all the ten years. It is interesting to note that every year there are periods during the summer season, when either the positive or the negative phases of the two oscillations reinforce each other and thereby change the seasonal mean vorticity by more than $50 \%$. This point is illustrated in table 3 where we compare 

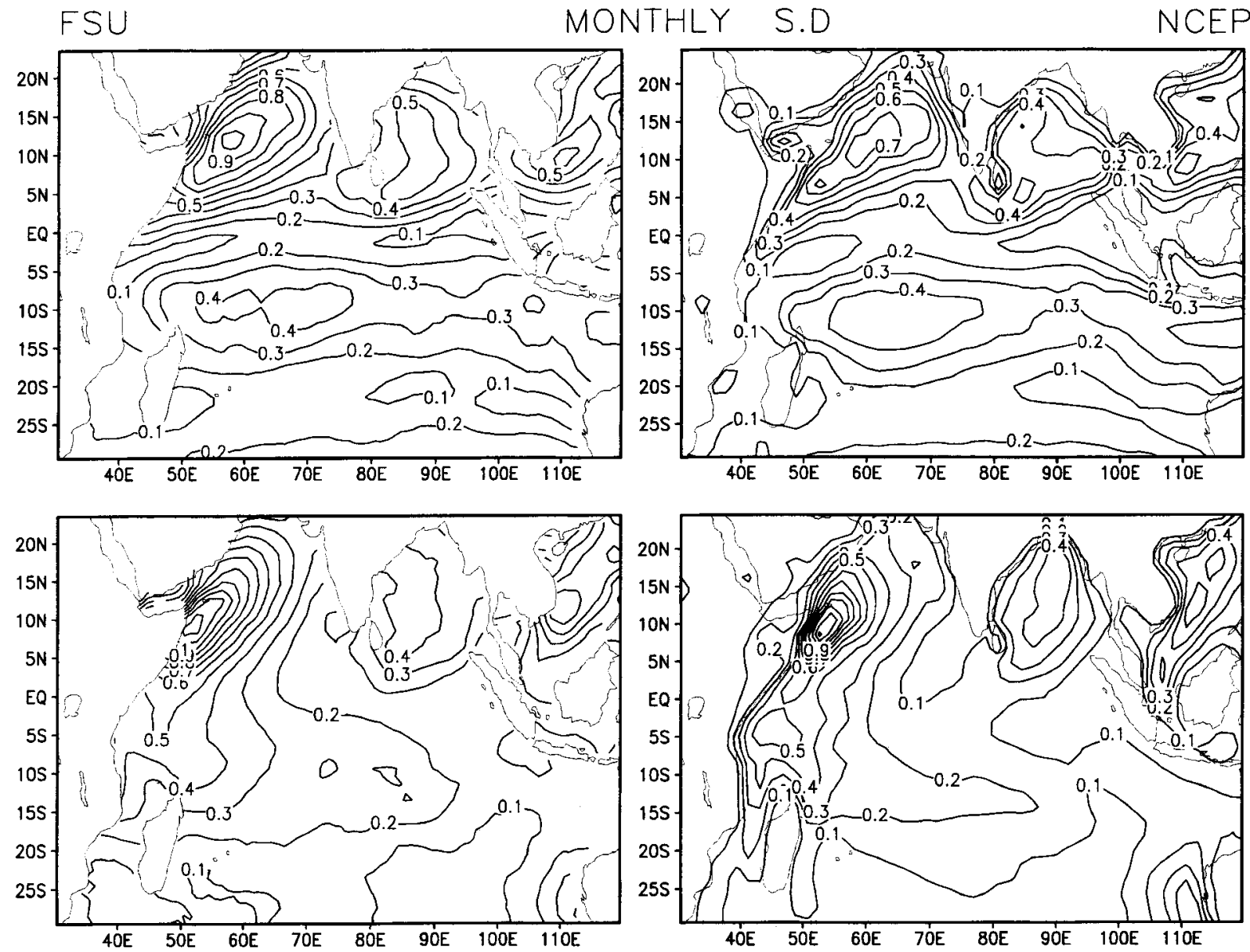

Figure 13. Interannual variability (standard deviation) of monthly zonal (upper) and meridional (lower) stresses in NCEP reanalysis (right panels) and in FSU analysis (left panels). Units are in dynes/cm². NCEP S.D is based on ten year data (19871996) while the FSU S.D is based on 14 years data (1979-1992).

vorticity averaged over the same region for the seasonal mean (June-September) with those associated with the 'active' phases of 30-60 day and 10-20 day oscillations.

\section{Monthly and seasonal means and their interannual variability}

In this section we compare the monthly mean surface wind stresses from the NCEP reanalysis with the independent Florida State University (FSU) analysis. For this purpose monthly mean zonal and meridional surface wind stresses were obtained from the FSU pseudostress objective analysis (Legler et al 1989) over the Indian monsoon region for the period 1979 to 1992. NCEP surface winds were also converted to stresses. The same drag coefficient $\left(C_{D}=0.0015\right)$ was used in deriving stress from both data sets. We examine surface stress in this section rather than wind so as to obtain information on the seasonal mean and interannual variability of the forcing for the ocean as well. Climatological mean summer and winter stresses from NCEP and FSU analyses are shown in figure 12, where the magnitude of the vector stress is depicted. Both the summer and winter mean NCEP reanalysed stresses agree well with the FSU analysis in location as well as in magnitude. Interannual variability of the surface stress as measured by standard deviation of the monthly mean stress from the two data sets are compared in figure 13. In this figure, the standard deviation of zonal and meridional stresses are separately compared. It is noted that the variability of the zonal stress over the Somali jet region is slightly underestimated in the NCEP reanalysis. The variability over the north Bay of Bengal, south China sea as well as the south equatorial trades agree well in the two analyses. The variability of meridional wind in the two analyses agree well in almost all regions. Good agreement between the two analyses on seasonal mean as well as in the interannual variability shows that no serious systematic bias is present in the NCEP reanalysis. Absence of bias allows us to assume that even on a daily time scale, the NCEP reanalyses would give reliable estimates of the surface winds, although there might be regions where observations are sparse on a day-to-day basis. 


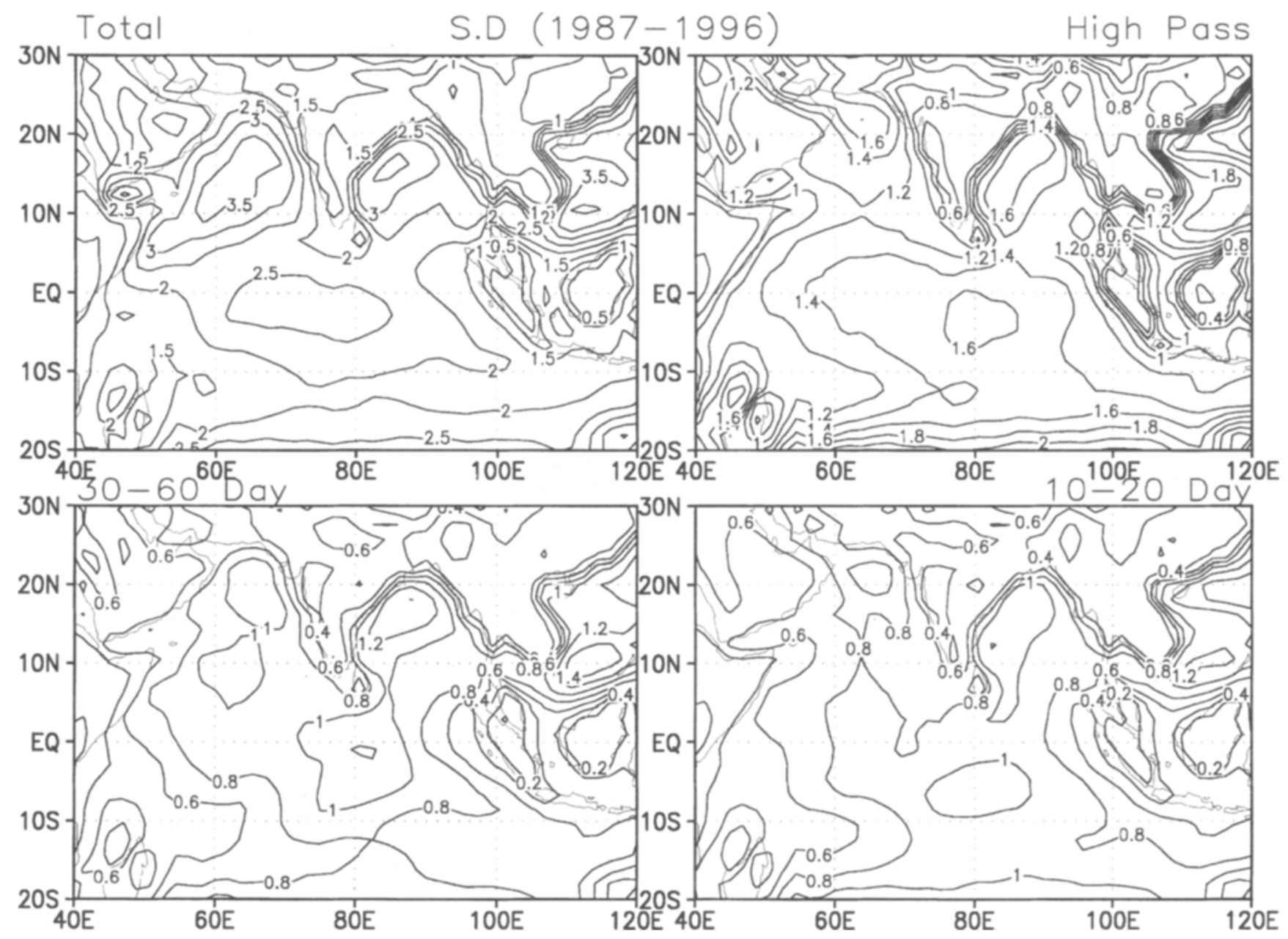

Figure 14. same as figure 4 but based on all ten (1987-1996) summers (May 1st to October 31st).

\section{Synoptic variability, ISOs and interannual variability}

In section 3, we showed that the spatial structure of variance of the ISOs correlates well with the spatial structure of the synoptic (i.e. high frequency) variance. The standard deviations averaged over all summers (May-October) of daily unfiltered zonal winds, the 30-60 day, 10-20 day and the high pass filtered zonal winds are shown in figure 14. It is clear that the location of maximum intraseasonal variance are also locations of maximum synoptic variance. Even though the ISOs by themselves explain only about $10-25 \%$ of the total daily variance, by controlling the synoptic variability they actually control a much larger fraction of the total daily variance. Co-location of the maxima of synoptic and intraseasonal variability by itself does not establish that the ISOs control synoptic activity. However, the circulation anomalies associated with the ISOs modify the large scale monsoon circulation in such a way that in one phase of the ISO, the synoptic activity is favoured while in another phase it is inhibited. This linkage is illustrated below.
The spatial structure of the climatological mean ISOs during the summer monsoon season is shown in figure 15. For this purpose, the mean of all peaks and troughs (i.e. categories 7 and 3) of the 30-60 day mode during the ten year period (1987-1996) is shown in this figure. Even after averaging over 10 years, the general structure of the vector wind anomalies and the vorticity patterns associated with the 'active' and 'break' phases are remarkably similar to figure 7 indicating the robustness of the spatial structure associated with the intraseasonal mode. Also striking is the opposite nature of the vector wind anomalies and the associated vorticity patterns for the two phases in the entire domain. Strengthening of the large scale monsoon circulation during 'active' phase of the ISO and associated enhancement of cyclonic vorticity over the monsoon trough region sets the stage for active synoptic activity in this region. Weakening of the monsoon trough during the 'break' phase suppresses synoptic activity. The vorticity pattern has the characteristic bimodal meridional structure discussed earlier. The bimodal character of the ISO is clearly demonstrated in figure 16 where the five-day running 


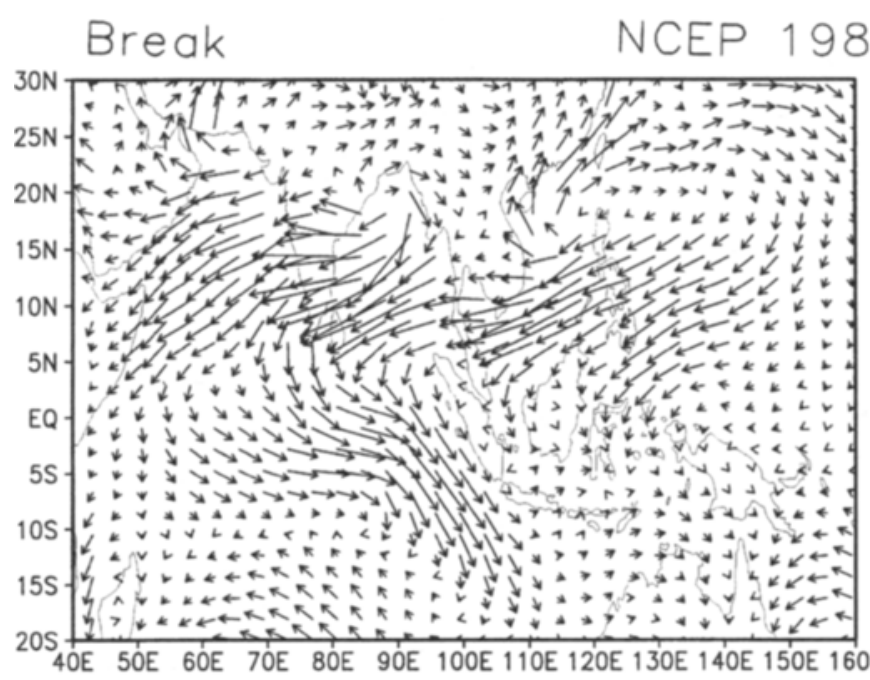

$87-96$

Active
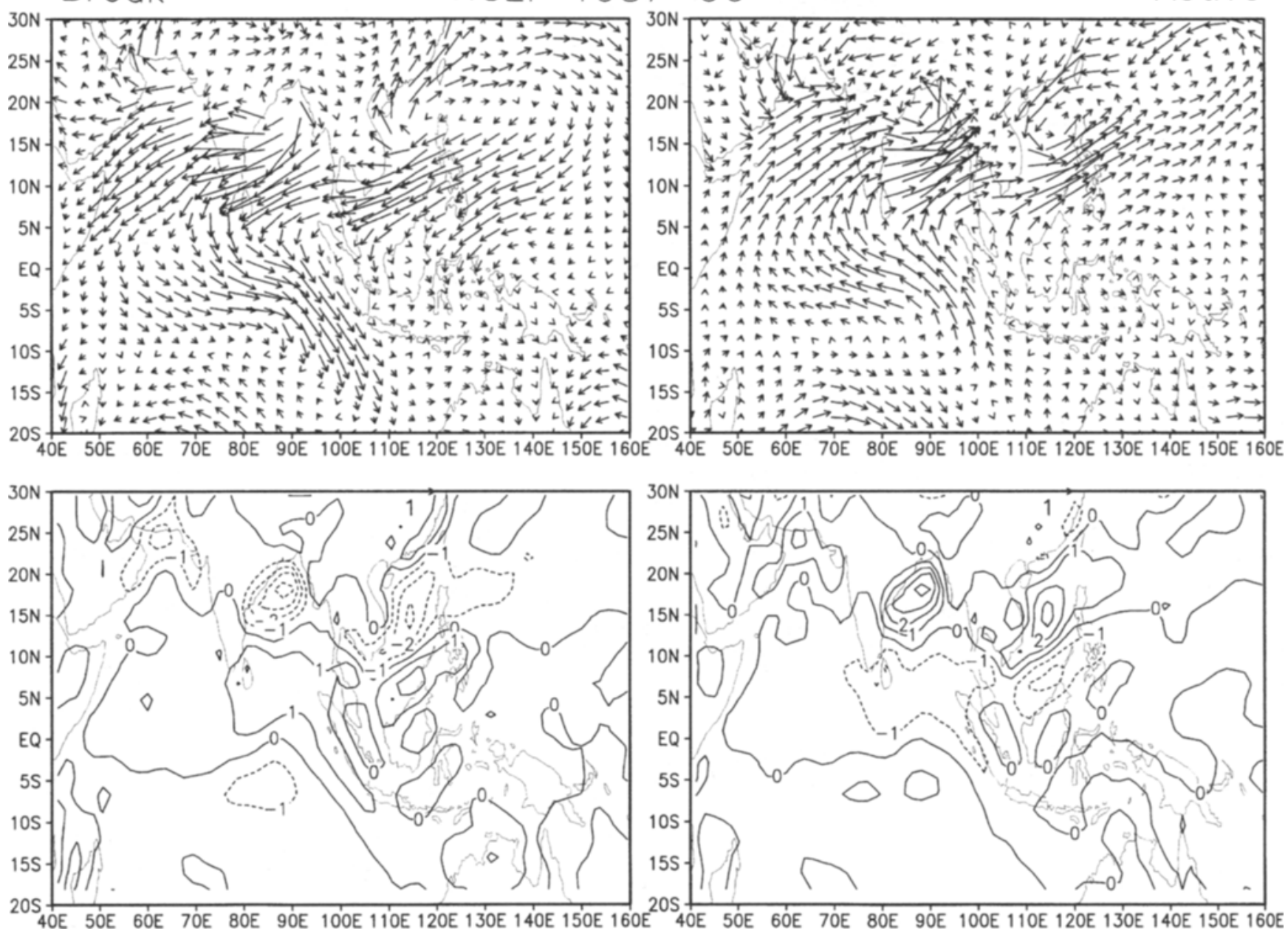

Figure 15. Climatological mean composite synoptic structure of the 30-60 day mode. Vector wind anomalies associated with 'active' and 'break' conditions (upper panels) and corresponding vorticity in units of $10^{-6} \mathrm{~s}^{-1}$ (lower panels).

mean vorticity averaged over the two nodes of the mode are shown during the ten summer seasons. A five-day running mean is used to eliminate high frequency component and focus on the combined effect of both ISOs. The strong negative correlation between the two shows that the bimodality is a robust feature. The bimodal structure of the intraseasonal mode is essentially a manifestation of the fluctuations of the TCZ between the two favoured positions as mentioned in section 1. An 'active' ('break') phase of the monsoon trough is also associated with positive (negative) relative vorticity anomaly over the oceanic TCZ between the equator and $10^{\circ} \mathrm{S}$ (figures 7 and 15 ), decreases (enhances) cyclonic vorticity and tends to weaken (strengthen) the TCZ over that region.

There is also a close connection between the ISO and the interannual variability of the mean winds. To investigate the structure of the interannual variability of the seasonal mean, we have used a compositing technique. For this purpose the Indian monsoon rainfall (IMR, Parthasarathy et al 1995) is used as reference to define strong and weak monsoons. Based on this, difference between surface winds averaged over two strong monsoon seasons $(1988,1994)$ and two weak monsoon seasons $(1987,1992)$ is created and plotted in figure 17 along with the associated vorticity pattern. Vector wind differences between pairs of 'strong' and 'weak' monsoon years (e.g. 1988-1987 and 1994-1992) have also been examined and found to be similar to figure 17 . This represents the dominant mode of interannual variability of the surface winds. It is interesting to note that a strong (weak) monsoon is associated with strengthening (weakening) of the large scale monsoon circulation. The vorticity in the Indian monsoon region between $40^{\circ} \mathrm{E}$ and $120^{\circ} \mathrm{E}$ bears close resemblance to the composite vorticity structure of the dominant intraseasonal mode (figure 15). The similarity between the structures of the intraseasonal and interannual variability over the Indian monsoon region is consistent with the hypothesis presented in the introduction regarding the relationship between ISOs and interannual variability. We would like to mention here that we did not use empirical orthogonal function analysis to bring out the interannual mode as 

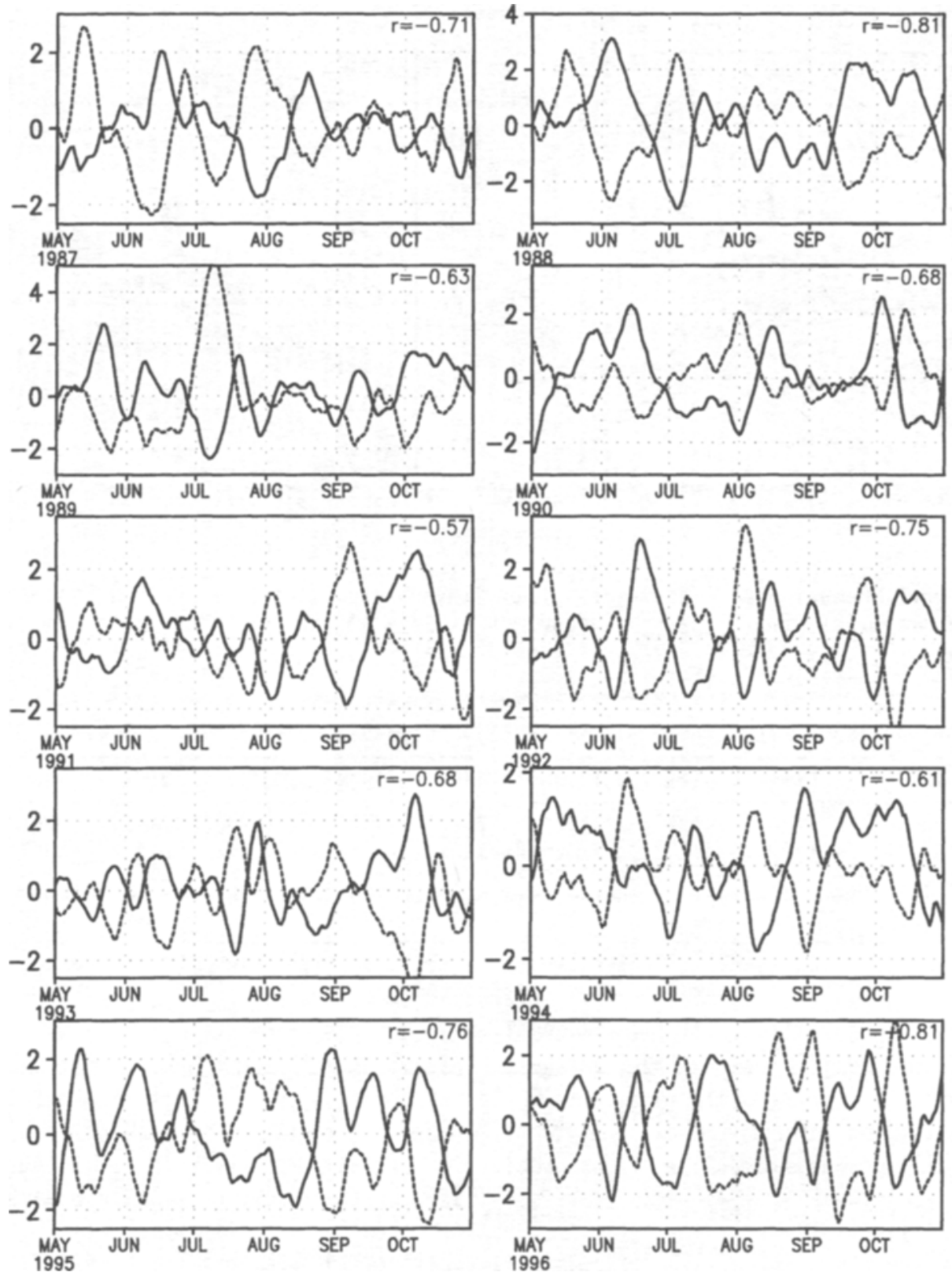

Figure 16. Bimodal character of the unfiltered daily vorticity between two preferred locations during the ten summer seasons. Time series of vorticity averaged over $\left(12^{\circ} \mathrm{N}-22^{\circ} \mathrm{N}, 70^{\circ} \mathrm{E}-100^{\circ} \mathrm{E}\right)$ and $\left(5^{\circ} \mathrm{S}-10^{\circ} \mathrm{N}, 70^{\circ} \mathrm{E}-100^{\circ} \mathrm{E}\right)$ are shown in units of $10^{-6} \mathrm{~s}^{-1}$.

ten seasons is rather too short to be used for this technique. The similarity in the patterns of intraseasonal and interannual variability of the surface winds indicates how the intraseasonal oscillations influence the interannual variability of the monsoon.

As described in the introduction this is likely to be accomplished by changes from one year to another in the residence time of the TCZ in the monsoon trough zone. We define that the TCZ is active in this zone if the vorticity averaged over the zone $\left(70-100^{\circ} \mathrm{E}\right.$, $12-22^{\circ} \mathrm{N}$ ) is greater than a critical value (taken as 1.75 $10^{-6} \mathrm{~s}^{-1}$ ). The residence time is calculated as the total number of days during the monsoon season (May 1st to September 30th) when the averaged unfiltered daily vorticity is greater than this value. This was calculated for all the years under consideration. In table 4, the residence time of the TCZ is compared with Indian monsoon rainfall (IMR) for the same years. For the two highly contrasting years, 1988 and 1987, the correspondence between the residence time and the monsoon activity is very strong. For the rest of the ten-year period, the relationship is not very strong. The correlation coefficient between the two series for the ten-year period is 0.8. Although the sample size is rather small, this result is supportive of our hypothesis regarding how the ISOs influence the seasonal mean. It would however, be desirable to examine this relationship with a longer data set. It may 

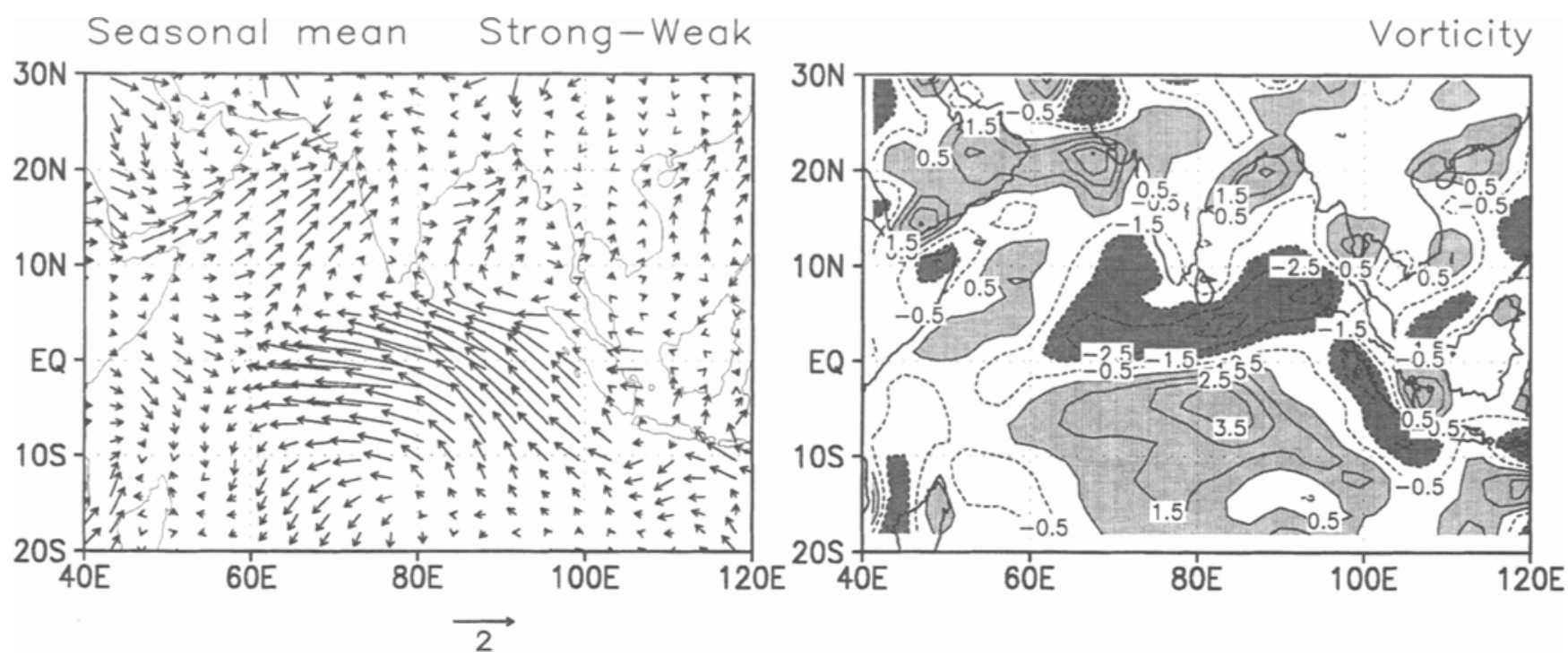

Figure 17. Vector wind difference $\left(\mathrm{ms}^{-1}\right)$ and corresponding relative vorticity $\left(10^{-6} \mathrm{~s}^{-1}\right)$ difference between 'strong' and 'weak' composite seasonal mean surface winds. 'Strong' (1988 and 1994) and 'weak' (1987 and 1992) monsoons are defined based on all India monsoon rainfall.

Table 4. Indian Monsoon Rainfall (IMR) and residence time of TCZ in its northern position (see section 6) for different years.

\begin{tabular}{lccccccccccc}
\hline Years & 1987 & 1988 & 1989 & 1990 & 1991 & 1992 & 1993 & 1994 & 1995 & 1996 & Mean \\
\hline IMR (mm) & 697 & 961 & 866 & 908 & 784 & 784 & 896 & 938 & 860 & 887 & 854 \\
Dep. from mean & $-18.2 \%$ & $12 \%$ & $1.7 \%$ & $6.6 \%$ & $-7.9 \%$ & $-7.9 \%$ & $5.2 \%$ & $10.1 \%$ & $0.9 \%$ & $4.1 \%$ & \\
Residence time & 15 & 39 & 31 & 25 & 22 & 26 & 28 & 28 & 30 & 35 & 27.9 \\
Dep. from mean & $-46 \%$ & $39.8 \%$ & $11 \%$ & $-10 \%$ & $-21 \%$ & $-6.8 \%$ & $0.4 \%$ & $0.4 \%$ & $7.5 \%$ & $25.5 \%$ & \\
\hline
\end{tabular}

also be noted that there is no theoretical framework at present to choose the critical value of the vorticity used to define the 'active' phase of the monsoon. The value used here is a rather subjective choice arrived at after examining the time series of the vorticity in that region for all the ten years.

\section{Conclusions}

The NCEP/NCAR reanalysed daily surface winds provide a reliable data set to study the intraseasonal oscillations (ISOs) of the surface winds and their interannual variations as it includes all possible delayed data and a stable analysis system. On the daily time scale, a comparison between the NCEP/ NCAR reanalysis and another independent data set is not attempted because such a reliable independent data set is not available. On the interannual time scale, a comparison of the NCEP/NCAR reanalysis with FSU analysis shows good agreement in the seasonal mean stress as well as interannual standard deviation of monthly stresses. This demonstrates that the NCEP/NCAR reanalysis does not have any major systematic bias on the monthly and interannual time scales arising from the analysis system (including the physical parameterizations used in the model). There- fore we expect the NCEP/NCAR reanalysis to be free of serious systematic bias even on the daily time scale.

The ISOs of the surface winds over the Indian monsoon region are studied using daily averaged NCEP/NCAR reanalysed surface winds for the period 1987-1996. Two dominant ISOs are found in all years, one with period between 30-60 days, and the other with period between 10-20 days. The 30-60 day mode is eastward propagating while the $10-20$ day mode is westward propagating. In the meridional direction, the 30-60 day mode tends to propagate northwards between $10^{\circ} \mathrm{N}-25^{\circ} \mathrm{N}$ in most years and is either stationary or southward propagating south of $10^{\circ} \mathrm{N}$. The 10-20 day mode is southward propagating south of $5^{\circ} \mathrm{N}$ in most years. It is either stationary or northward propagating north of $5^{\circ} \mathrm{N}$. Although the ISOs explain only about $10-25 \%$ of the daily variance, the spatial structure of intraseasonal variance bears close similarity with that of the synoptic variance indicating a strong association between the ISOs and synoptic variations. It is shown that this association results from the ISOs modulating the large scale mean monsoon circulation in such a way that in one phase of the oscillation they favour vigorous synoptic activity while in the other phase they inhibit it. The spatial structure of the 30-60 day mode is similar in all years and is shown to be intimately related to the 
strong ('active') or weak ('break') phases of the Indian summer monsoon circulation. The peak (trough) phase of the ISOs at a point in the north Bay of Bengal corresponds to the 'active' ('break') phase of monsoon strengthening (weakening) the large scale monsoon circulation. In the 'active' phase, a strong 'monsoon trough' enhances synoptic activity while in the 'break' phase, a weakened 'monsoon trough' suppresses them. The peak wind anomalies associated with these ISOs could be as large as $30 \%$ of the seasonal mean winds in many regions. The vorticity pattern associated with the synoptic structure of the 30-60 day mode has a bimodal meridional structure similar to the one associated with the seasonal winds but with a smaller meridional scale. The synoptic structure of the 10-20 day mode is similar to that of the 30-60 day mode but is weaker almost everywhere except over the north Bay of Bengal where the vorticity associated with this mode is comparable to that associated with the $30-60$ day mode. The bimodal meridional structure of the ISOs is consistent with the conceptual picture presented in the introduction that the ISOs result from a fluctuation of the TCZ between the two favoured locations.

It is also discovered that the composite structure of the 30-60 day mode is strikingly similar to the dominant mode of interannual variability of the seasonal mean winds, indicating a strong link between the ISOs and the seasonal mean. It is noted that both the 'active' (break) phase of the 30-60 day oscillation and 'strong' (weak) case of the interannual variability represent a large scale enhancement (weakening) of the seasonal mean monsoon circulation. This similarity between the spatial structures of the dominant intraseasonal and interannual variability is the key to understanding how the ISOs influence the seasonal mean and its interannual variability. The seasonal mean is stronger (weaker) than normal in a year characterized by either more frequent 'active' (break) spells or by more intense 'active' (break) spells. In other words the residence time of the ISOs in the 'active' (break) mode and the enhancement (weakening) of the cyclonic vorticity in the northern belt determines interannual variability of monsoon circulation and Indian monsoon activity. Thus, the ISOs seem to act as a catalyst to control much of the variability in this region with synoptic variability at one end of the spectrum and interannual variability at the other. This scenario is consistent with a conceptual model of monsoon variability described by Goswami (1994) and summarized in section 1. It is also shown that in the Bay of Bengal region, the wind curl associated with the peak phases of the ISOs could be as large as $50 \%$ of the seasonal mean wind curl. Hence, ISOs in this region could drive significant ISOs in the ocean and could influence the seasonal mean currents in the Bay.

\section{Acknowledgement}

The authors are grateful to the Department of Science and Technology, Government of India, for partial support through a grant and the Supercomputing Education and Research Centre, Indian Institute of Science, Bangalore for computing facilities.

\section{References}

Ahlquist J, Devaras A and Carlo T 1990 Intraseasonal monsoon fluctuations seen through 25 years of Indian radiosonde observations; Mausam 41 273-278

Dakshinamurti J and Keshavamurthy R N 1976 On oscillations of period around one month in the Indian summer monsoon; Indian J. Meteorol. Geophys. 27 201-203

Ferranti L, Slingo J M, Palmer T N and Hoskins B J 1997 Relations between interannual and intraseasonal monsoon variability as diagnosed from AMIP integration; $Q . J . R$. Meteorol. Soc. 123 1323-1357

Gadgil S 1988 Recent advances in Indian monsoon research with particular reference to Indian monsoon; Australia Meteorol. Mag. 36 193-205

Goswami B N 1994 Dynamical predictability of seasonal monsoon rainfall. Problems and prospects; Proc. Indian Natl. Sci. Acad. 60A 101-120

Hartman D and Michelson M I 1989 Intraseasonal periodicities in the Indian rainfall; J. Atmos. Sci. 46 2838-2862

Kalnay E et al 1996 The NCEP/NCAR 40 years reanalysis project; Bull. Am. Meteorol. Soc. 77 437-471

Keshavamurthy R N 1973 Power spectra of large scale disturbances of Indian southwest monsoon; Indian $J$. Meteorol. Geophys. 24 117-124

Krishnamurti $\mathrm{T} N$ and Bhalme H N 1976 Oscillation of monsoon system. Part I: observational aspects; J. Atmos. Sci. 45 1937-1954

Krishnamurti T N and Ardanuy P 1980 The 10 to 20 day westward propagating mode and 'Breaks in the Monsoon'; Tellus 32 15-26

Krishnamurti T N and Subramanian D 1982 The 30-50 day mode at $850 \mathrm{mb}$ during MONEX; J. Atmos. Sci. 39 2088-2095

Legler D M, Navon I M and O'Brein J J 1989 Objective analysis of pseudostress over the Indian Ocean using a direct minimization approach; Mon. Weather Rev. 117 709-720

Mehta V M and Krishnamurti T N 1988 Interannual variability of 30-50 day wave motions; J. Meteorol. Soc. Japan. $66535-548$

Murakami M 1979 Large scale aspects of deep convective activity over the GATE area; Mon. Weather Rev. 107 994-1013

Murakami T, Nakazawa T and He J 1984 On the 40-50 day oscillation during 1979 northern hemispheric summer Part I: Phase propagation; J. Meteorol. Soc. Japan 62 440-468

Murakami T and Nakazawa $T 1985$ Tropical 45 day oscillation during the 1979 northern hemisphere summer; J. Atmos. Sci. 42 1107-1122

Parthasarathy B, Munot A A and Kothawale D R 1995 Monthly and seasonal rainfall series for all India, homogeneous regions and meteorological subdivisions: 1871-1994; Indian Institute of Tropical Meteorology Research Report No. RR065, ISSN 0252-1075, IITM, Homi Bhabha Road, Pune 411008, India.

Schott F, Reppin J, Fischer J and Quadfasel D 1994 Currents and transports of the monsoon current south of Sri Lanka; $J$. Geophys. Res. 99 25127-25141

Sikka D R and Gadgil S 1980 On the maximum cloud zone and the ITCZ over Indian longitudes during the southwest monsoon; Mon. Weather Rev. 108 1840-1853 
Singh S V and Kripalani R H 1990 Low frequency intraseasonal oscillations in Indian rainfall and outgoing longwave radiation; Mausam 41 217-222

Singh S V, Kripalani R H and Sikka D R 1992 Interannual variability of the Madden-Julian oscillation in Indian summer monsoon rainfall; $J$. Climate 5 973-978

Trenberth K E and Olson J G 1988 An evaluation and intercomparison of global analysis from the National Meteorological Centre and Europian Centre for Medium Range Forecasts; Bull. Am. Meteorol. Soc. 69 1047-1058
Yasunari T 1979 Cloudiness fluctuations associated with the northern hemisphere summer monsoon; $J$. Meteorol. Soc. Japan 57 227-242

Yasunari $\mathrm{T} 1980 \mathrm{~A}$ quasi stationary appearance of 30-40 day period in the cloudiness fluctuations during the summer monsoon over India; J. Meteorol. Soc. Japan 58 225-229

Yasunari T 1981 Structure of an Indian summer monsoon system with around 40-day period; J. Meteorol. Soc. Japan 59 336-354 